Portland State University

PDXScholar

Summer 8-8-2019

\title{
Early Intervention Referral Outcomes for Children at Increased Risk of Experiencing Developmental Delays
}

Kristi Laurine Atkins

Portland State University

Follow this and additional works at: https://pdxscholar.library.pdx.edu/open_access_etds

Part of the Educational Leadership Commons, and the Special Education and Teaching Commons Let us know how access to this document benefits you.

Recommended Citation

Atkins, Kristi Laurine, "Early Intervention Referral Outcomes for Children at Increased Risk of Experiencing Developmental Delays" (2019). Dissertations and Theses. Paper 5100.

https://doi.org/10.15760/etd.6976

This Dissertation is brought to you for free and open access. It has been accepted for inclusion in Dissertations and Theses by an authorized administrator of PDXScholar. Please contact us if we can make this document more accessible: pdxscholar@pdx.edu. 
Early Intervention Referral Outcomes for Children at Increased Risk of Experiencing Developmental Delays

\author{
by \\ Kristi Laurine Atkins
}

A dissertation submitted in partial fulfillment of the requirements for the degree of

\author{
Doctor of Education \\ in \\ Educational Leadership: Special and Counselor Education
}

Dissertation Committee:

Sheldon Loman, Chair

Amy Donaldson

Moti Hara

Dot McElhone

Portland State University

2019 
(C) 2019 Kristi Laurine Atkins 


\begin{abstract}
Research has shown that children born low birth weight (i.e., $\leq 2500$ grams) and/or premature (i.e., birth prior to 37 weeks gestation) are at increased risk of experiencing developmental delays, as well as long-standing executive functioning and academic challenges. Despite these well-known risks, children born low birth weight are underenrolled nationally in Part C Early Intervention (EI) services intended to support developmentally vulnerable children. Little is known regarding why EI enrollment is low in this high risk population, especially given children born LBW are readily identifiable as at increased risk of delays at birth. This study explored EI referral outcomes from a high risk infant follow up program serving children with complex early medical histories that place them at increased risk of experiencing developmental delays to determine how many children referred to EI were ultimately evaluated and enrolled in the program. This explanatory sequential mixed methods study included a quantitative phase characterizing the EI referral outcome and a qualitative phase consisting of interviews with families to explore the parent/caregiver's experience of the EI referral process. Data analysis included descriptive statistics to characterize the sample and Pearson Chi Square and independent samples t-tests to investigate child characteristics associated with successful referral. Qualitative interviews were transcribed and coded for themes in an iterative and cyclical fashion. Results indicate that only $62 \%$ of the children who were referred for EI services were evaluated by the program, with about the same percentage of those evaluated being found eligible (67\%). Of those who were not found eligible, about a third of children should have qualified based on previous testing and/or medical conditions.
\end{abstract}


However, these qualifying medical conditions were often not clearly documented on the referral form, and not all forms included documentation of the scores from developmental testing. There were also a significant number (71\%) of Oregon children referred to EI but never evaluated who were likely to have qualified based on medical history and/or results from developmental testing. There were several key themes identified following analysis of the qualitative interviews. Most critically, the parent/caregiver's perception of the need for the EI referral was identified as an essential factor in facilitating a successful connection to EI. Other key themes included the need to honor the many different demands placed on the caregivers of these high risk children, as well as the necessity of providing clear explanation of the purpose of both the visit to the high risk infant follow up program and the EI referral. The Chronic Care Model is used as a framework for discussing implications for practice. 


\section{Acknowledgements}

I am grateful to my committee members and my peers in the doctoral program for their ongoing support, feedback, and guidance. I would also like to thank my colleagues at OHSU, particularly Susanne Duvall, Sage Saxton, Patricia Blasco, Jill Dolata, Kylie Sage, and Shannon Theis. Special thanks to my research assistants, Kim Bui and Nika Griffith. This work is dedicated to my daughter, Eloise, who inspires me to be my best every day. 


\section{Table of Contents}

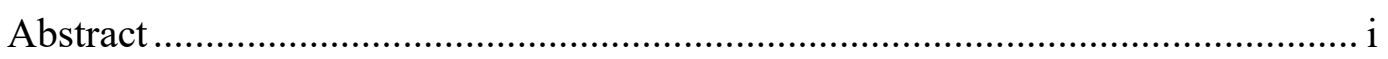

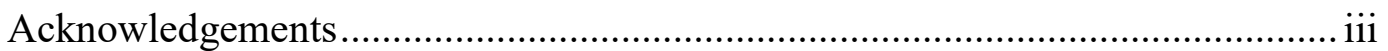

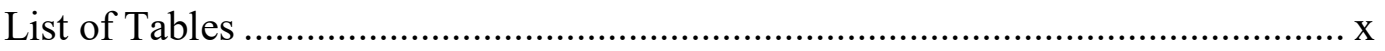

List of Figures ..........................................................................................

Chapter 1: Problem Statement ..................................................................... 1

Problem Description and Background ..................................................... 1

Research Problem Statement ...................................................................... 4

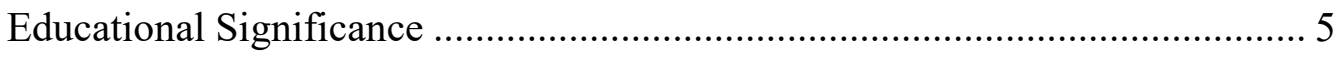

Benefits of Early Intervention................................................................. 5

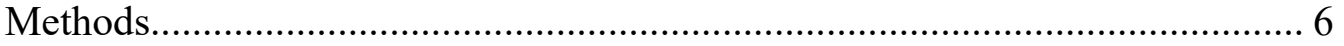

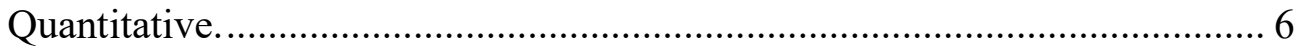

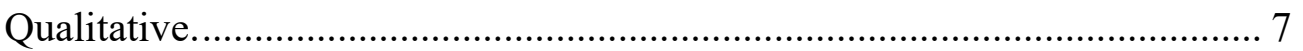

Research Objectives........................................................................... 7

Research Questions ............................................................................... 7

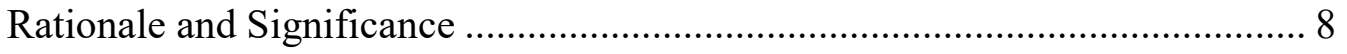

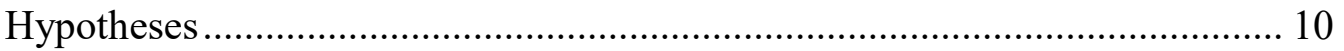

Definitions of Key Concepts/Organization Descriptions ............................. 10

Low Birth Weight. ....................................................................... 10 


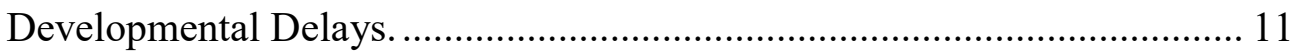

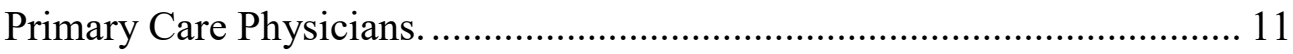

Part C early intervention programs............................................................... 12

High risk infant follow up program. ............................................................. 12

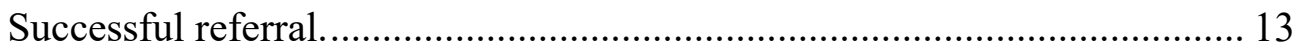

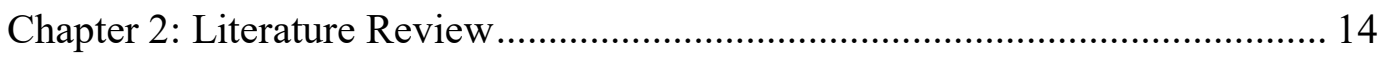

Barriers to Successful Early Intervention Enrollment ...................................... 14

Factors predicting early intervention enrollment in the general population. 14

Factors predicting early intervention enrollment for children born low birth

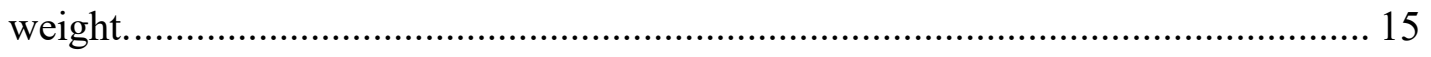

The early intervention referral process. ..................................................... 18

Early intervention referral outcomes in the general population..................... 20

Early intervention referral opportunities for children born low birth weight.

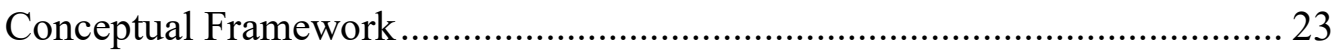

Low birth weight/prematurity as a chronic health condition....................... 23

Challenges connecting infants born low birth weight with early intervention.

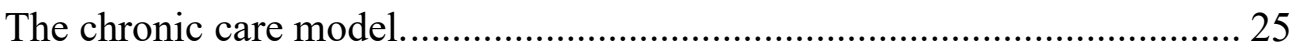


Self-management support. ......................................................... 26

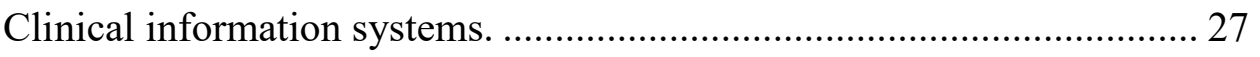

Delivery system redesign and decision support................................. 27

Health care organization. .......................................................... 28

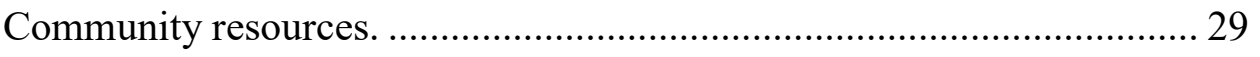

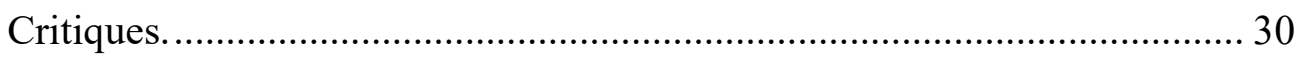

Theoretical Framework ............................................................................ 30

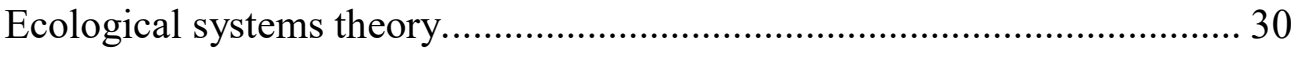

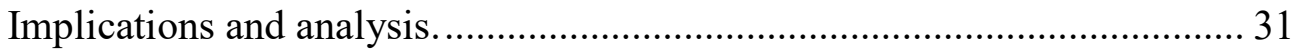

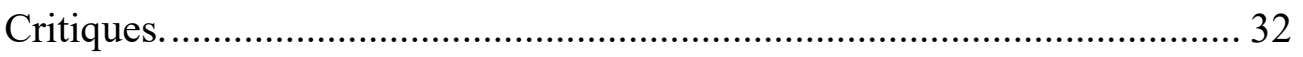

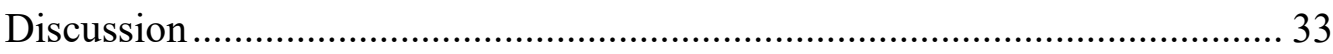

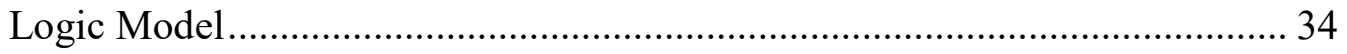

Review of the Methodological Literature ................................................. 35

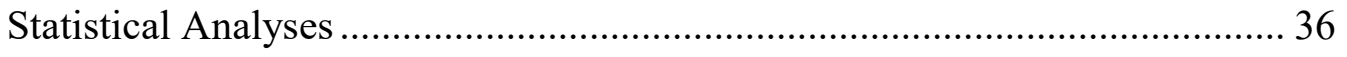

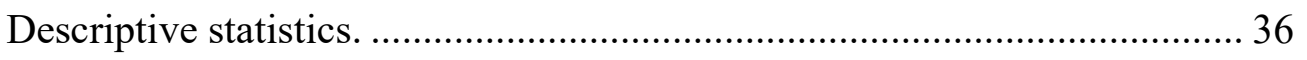

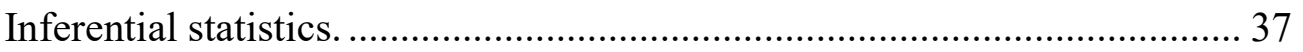

Summary of the Research Literature and Application to the Study ................ 37

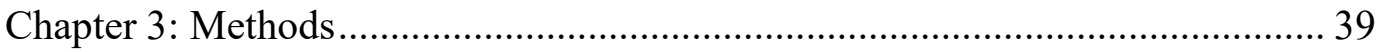

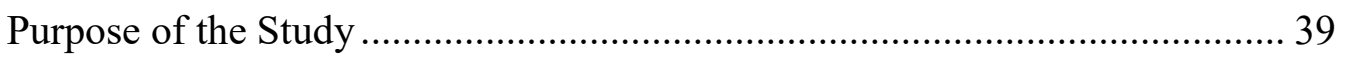


Quantitative Phase Research Methods ........................................................... 40

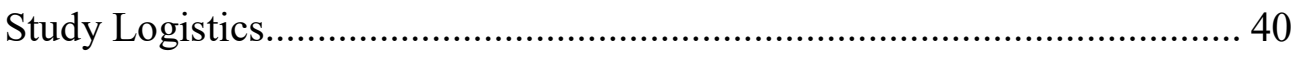

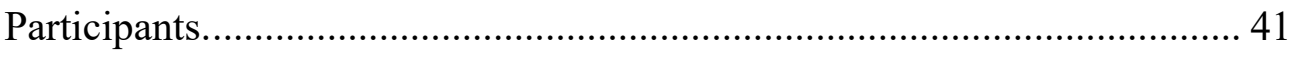

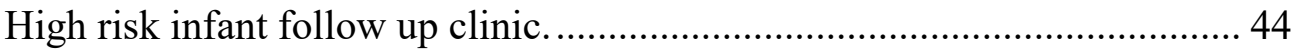

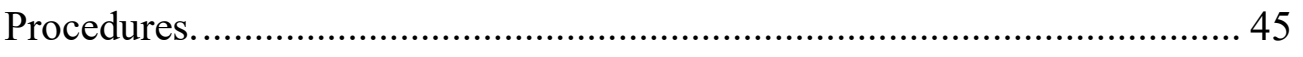

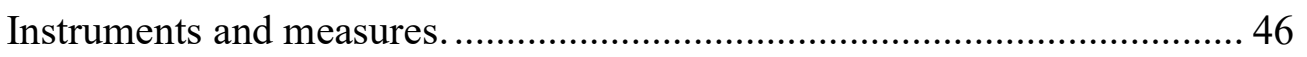

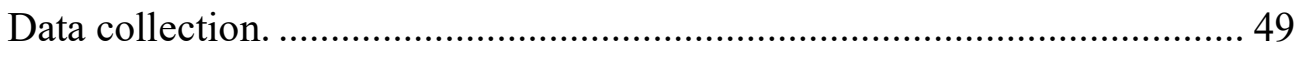

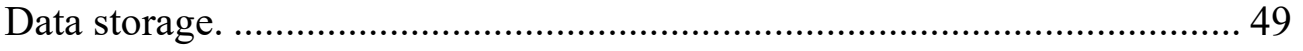

Qualitative Phase Research Methods................................................................ 49

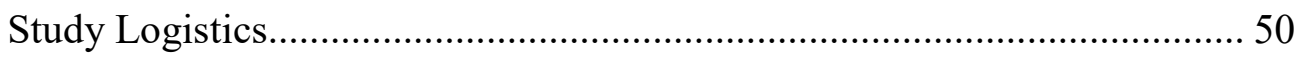

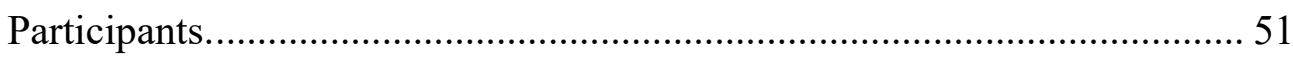

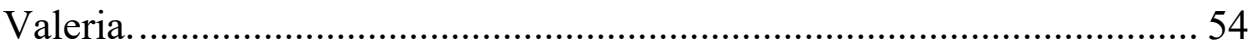

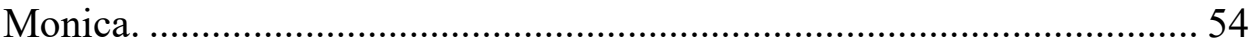

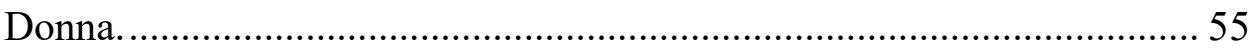

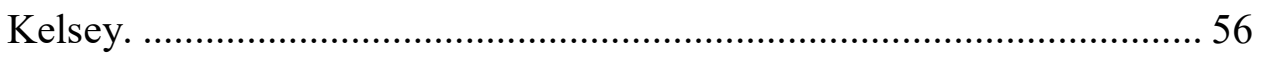

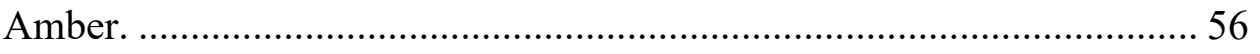

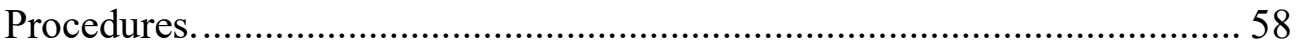

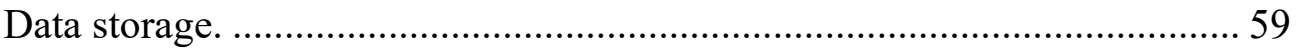

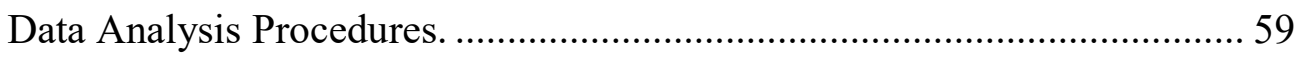




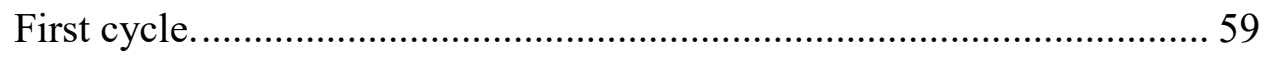

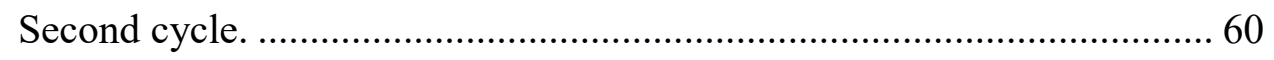

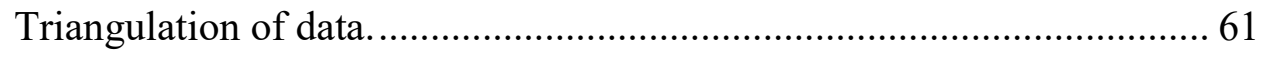

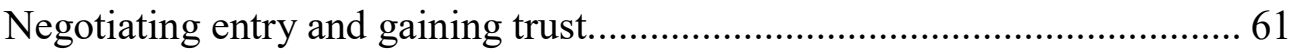

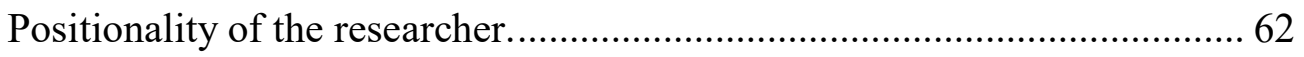

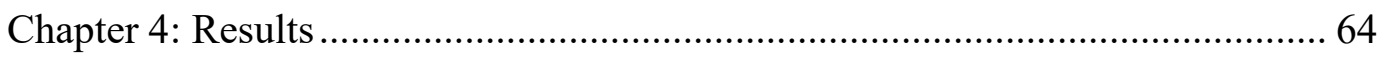

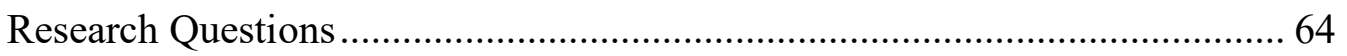

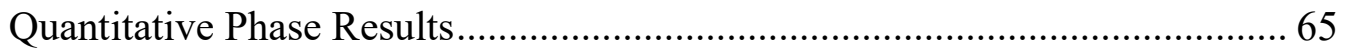

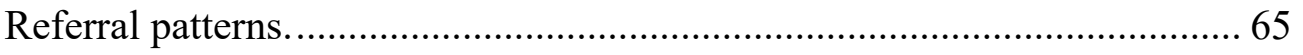

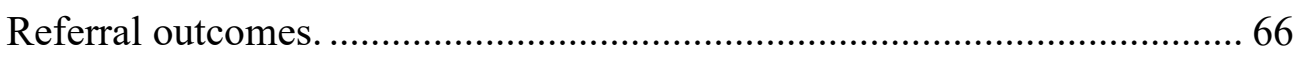

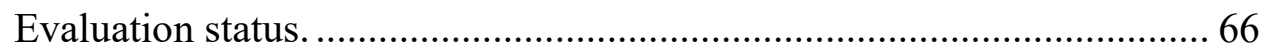

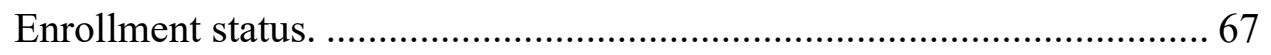

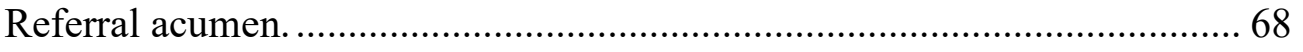

Factors associated with successful EI referral. .............................................. 70

Referral outcomes by birth weight category............................................ 75

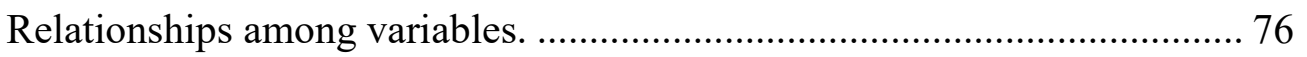

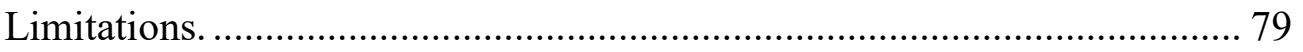

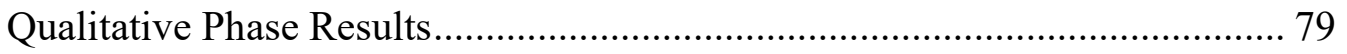

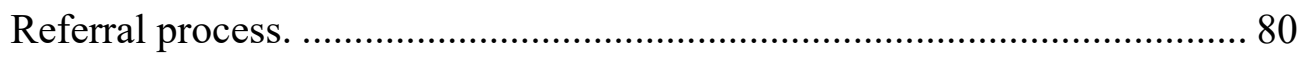


EARLY INTERVENTION ENROLLMENT $\quad$ ix

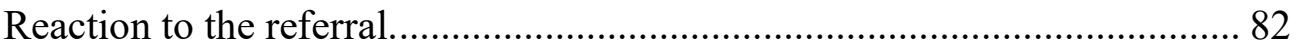

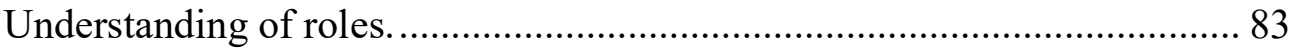

Factors influencing referral outcome.................................................. 87

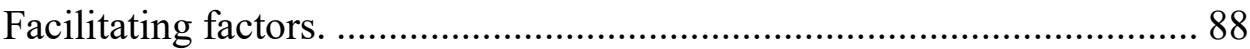

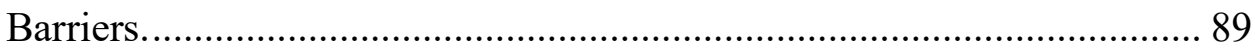

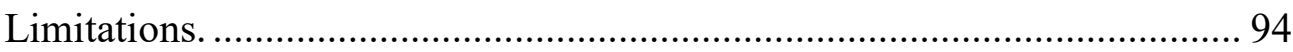

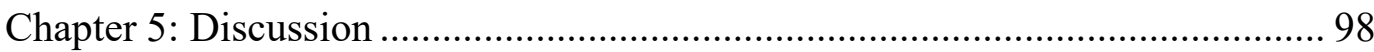

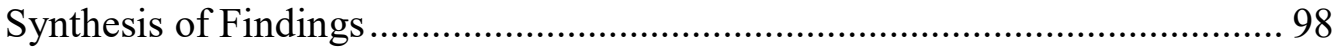

Implications for Practice ........................................................................... 103

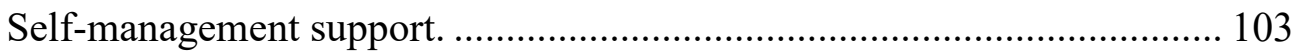

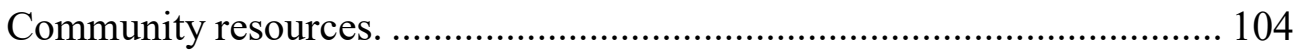

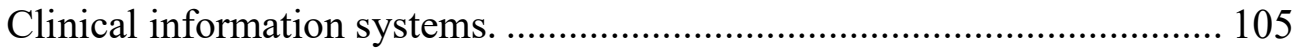

Delivery system redesign and decision support................................... 106

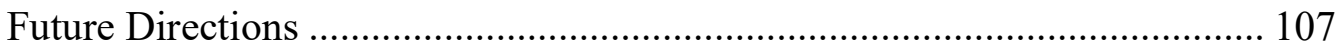

Conclusions ...................................................................................... 108

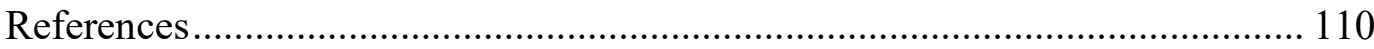

Appendix A: Interview Protocol .................................................................. 119

Appendix B: Final Code List .................................................................... 124 


\section{List of Tables}

Table

Table 1. Characteristics of Low Birth Weight Children Seen in the High Risk Infant

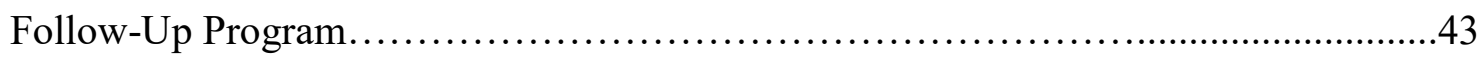

Table 2. Reliability and Stability Coefficients of the Subtests and Composites for All Ages.................................................................. 48

Table 3. Interview Participant Characteristics...................................53

Table 4. Referral Concerns for Children Referred to Early Intervention...............65

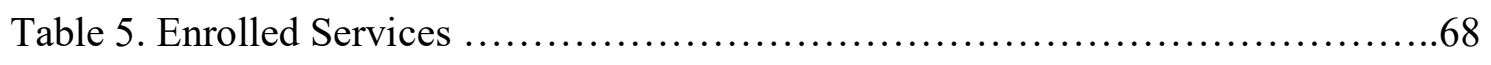

Table 6. Categorical Eligibility for Oregon Children not Evaluated .................69

Table 7. Participant Characteristics by Evaluation Status.......................... 72

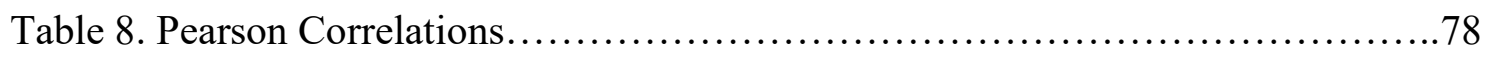




\section{List of Figures}

Figure $\quad$ Page

Figure 1. Reported Reason not Evaluated by Early Intervention ...................67

Figure 2. Evaluation Status by BirthweightCategory............................. 75 


\section{Chapter 1: Problem Statement}

\section{Problem Description and Background}

In 2016, there were about 322,375 children born low birth weight (LBW, $\leq 2500$ grams) in the United States, which accounted for $8.17 \%$ of all births nationally (Martin, Hamilton, Osterman, Driscoll, \& Drake, 2018). This number represents a slight increase in children born LBW from the previous year, a percentage which has been trending upward since hitting a low of 7.99\% in 2012 (Martin et al., 2018). Historically, healthcare providers and educators assumed that once medically stabilized, children born LBW without frank cerebral damage (e.g, those who do not have a brain bleed, seizure activity, or hypoxic event) caught up readily to their peers developmentally. However, multiple studies have shown that not only are children born LBW at increased risk of experiencing conditions associated with pervasive developmental disorders (e.g., cerebral palsy, intellectual disability), even those born without apparent cerebral injury are at increased risk for developmental delays, executive functioning challenges, and more nuanced linguistic and academic challenges (Barre, Morgan, Doyle, \& Anderson, 2011; Duvall, Erickson, MacLean, \& Lowe, 2015; Guarini et al., 2009; Hutchinson, De Luca, Doyle, Roberts, \& Anderson, 2013; Johnson, 2007; Lee, Yeatman, Luna, \& Feldman, 2010). Despite known increased risk for experiencing developmental delays, LBW infants are under-served in Part C Early Intervention (EI) programs nationally (Hebbeler et al., 2007). As described in IDEA (2004), Part C Early Intervention (EI) services provide intervention and developmental support to qualifying children and their families 
from birth until three years of age, at which time the child is re-evaluated and either discharged from services or transitioned into Part B Early Childhood Special Education (ECSE) services. Though families can self-refer to EI, the main referral source is primary care physicians in the community (Hebbeler et al., 2007).

In order to be eligible for Part C services according to IDEA (2004), children must either demonstrate developmental delays on standardized testing or have an established medical condition that automatically confers eligibility based on the condition's likelihood of resulting in developmental delays or disorders (e.g., cerebral palsy, Down syndrome, autism spectrum disorder, neurosensory impairment). Since each state is left to determine their own eligibility criteria for EI enrollment (i.e., what diagnosed conditions confer automatic eligibility and what constitutes developmental delays on assessment), it is difficult to obtain reliable estimates on the number of children across the nation who would likely qualify for EI. However, in an attempt to provide a national estimate of service utilization, Rosenberg, Zhang, and Robinson (2008) created a nationally representative longitudinal sample of children born in 2001 in the United States to investigate participation in Part C services as it relates to developmental status at nine and 24 months. They determined about $10 \%$ of children who are likely to be eligible for Part C services are enrolled. Follow up investigation looking at differences across states revealed the proportion of children who would likely qualify for services ranges from $2 \%$ to $78 \%$, while the number of children actually enrolled in services ranges from $1.5 \%$ to just under $7 \%$ (Rosenberg, Robinson, Shaw, \& Ellison, 2013). These significant discrepancies in service utilization across states are largely due to the high levels of 
variability both in how states define developmental delays (i.e., how delayed a child must be in a specific number of developmental domains in order to qualify for services and which medical conditions confer categorical eligibility.

Unfortunately, this national pattern of under-enrollment also holds true for infants with complicated early medical histories that place them at increased risk of experiencing developmental delays, including those born LBW (Barfield et al., 2008; Blasco, Guy, Saxton \& Duvall, 2017; Litt \& Perrin, 2014). State-specific research has shown that barriers to successful EI enrollment for LBW infants include lack of a formal referral tracking process and poor communication between referring providers and EI programs (Little, Kamholz, Corwin, Barrero-Castillero, \& Wang, 2015). Though there is currently no national standard for EI eligibility related to children born LBW, a recent position statement by the Division for Early Childhood of the Council for Exceptional Children (2017) recommended that birth weight less than 1,500 grams and/or birth at less than 37 weeks gestation be used a national standard for categorical EI eligibility. Furthermore, recommendations for improving EI referral outcomes for preterm and LBW infants include faxing referrals directly to EI programs rather than simply providing the family with a phone number (Jimenez, et al., 2014) and following up on referral outcomes (Little, et al., 2015). Limited data from previous research suggests some children born LBW may not be in services due to be difficulty connecting with the program or not being found eligible upon evaluation (Blasco et al., 2017). Though under-enrollment of LBW children in EI services is well documented, there is little research examining why this is the case. Specifically, there is currently no research systematically investigating EI 
referral outcomes for high risk infants (e.g., children born LBW). Additional information regarding why some children are missed for referral/enrollment to EI services early on is critical to inform eventual policy change and/or programmatic restructuring (Twardzik, Cotto-Negron, \& MacDonald, 2017).

\section{Research Problem Statement}

Children born LBW are at-risk for developmental delays and would likely benefit from early intervention (EI) services. While several research studies have shown that children born LBW are under-enrolled in EI services (Atkins, Duvall, Dolata, Blasco, \& Saxton, 2017; Blasco et al., 2017; Hebbeler et al., 2007; Litt \& Perrin, 2014; Tang et al., 2012), there has been no systematic investigation regarding why this is the case. Based on clinical experience, many EI referrals placed by physicians are not ultimately successful (i.e., do not result in a child being evaluated and/or reviewed for eligibility by the program and enrolled in services), for unknown reasons. The purpose of this study was to examine EI referral outcomes from a high risk infant follow up program serving children born LBW, as well as the factors associated with successful referral. An additional aim of the study was to explore the experiences of families of children referred to EI from the high risk infant follow up program. The quantitative portion of this study also investigated the relationship between particular characteristics of the child and/or family and successful EI enrollment. The qualitative component of this study explored family perspectives regarding EI referral procedures from one high risk infant follow up program, as well as ideas for improvement. Results from this explanatory sequential mixed methods study will be used to inform a quality improvement project to advance 
clinical care for children born LBW by improving referral procedures and care coordination efforts from one regional high risk infant follow up clinic.

\section{Educational Significance}

Benefits of Early Intervention. EI services are beneficial for supporting the ongoing development of children who are experiencing developmental delays or have a medical condition that places them at risk for developmental delays, as well as for their families. In addition to examining developmental outcomes, data from the National Early Intervention Longitudinal Study (NEILS) has been used to explore what caregivers consider the perceived benefit of EI services. Bailey et al. (2005) used the NEILS data to identify 2,586 families across 20 states whose children were about 36 months of age and had participated in EI services at some point and conducted phone interviews regarding their experiences. The researchers found $82 \%$ of families believed they had benefited from participating in an EI program. The authors also found that most of the parents in the study felt competent in caring for their children (an important factor given that some children with developmental delays also have complex medical needs), advocating for services, and accessing formal and informal supports.

Additional data on caregiver perception regarding the benefit of participation in EI from the NEILS study (Hebbeler et al., 2007), indicated 76\% of families reported that EI had "a lot of impact"; $20 \%$ reported it had "some impact"; and only $4 \%$ indicated that EI had "no impact." There were some differences in reported impact based on how long a child had participated in the program, with only $61 \%$ of families who had left EI early

(i.e., prior to 36 months) indicating EI had "a lot of impact." There were no data available 
in this study regarding why families may have left EI prior to 36 months, though the authors speculated that children served under conditions that placed them at risk for delays may not have needed developmental supports, or that families who chose to leave early may have been more likely to be dissatisfied with services.

There is less information available regarding utility of EI services specifically for children determined to be at increased risk for experiencing developmental delays due to their medical history. However, a recent study by Litt, Glymour, Hauser-Cram, Hehir, and McCormick (2017), investigated the effects of EI enrollment in children born at increased risk for developmental delays (most were LBW) on functional outcomes in kindergarten. They found that children who were late to enroll in EI were less likely to have average academic and physical skills than children with more timely entrance into the program. Furthermore, the results of the study indicated that longer and more intensive EI services were associated with higher academic and physical skills in kindergarten. Ultimately, EI programs have been shown to be beneficial to children at increased risk of experiencing developmental delays and their families. However, research has revealed significant challenges in connecting children successfully with the program (Williams, Perrigo, Banda, Matic, \& Goldfarb, 2013).

\section{Methods}

Quantitative. The quantitative phase of this study consisted of an observational investigation using a clinical sample. As described in Creswell (2014), observational/correlational research is intended to investigate the degree to which two or more variables are related to a variable of interest. This design was chosen as it was the 
best fit to determine what was happening after EI referrals were placed by a physician, given that the independent variables consisted of intrinsic characteristics of the child that could not be controlled for or manipulated. This portion of the study investigated which child factors were associated with successful EI enrollment.

Qualitative. The qualitative phase of this study included semi-structured interviews with families of children referred from the high risk infant follow up program. This phase of the study attempted to contextualize the quantitative results, as well as to explore why some children were not successfully referred to EI, from the perspective of the family.

\section{Research Objectives}

The objectives of this study were to (a) investigate EI referral outcomes for LBW children directly referred to EI following an evaluation in a high risk infant follow-up program, (b) gain information regarding factors associated with successful referral outcome, and (c) explore caregivers experiences with the EI referral process and their perspectives on why some children have difficulty connecting with the program.

\section{Research Questions}

1. To what extent are the children referred to Early Intervention from the high risk infant follow up clinic connected with their local EI program at the time of follow up phone call (i.e., have they been evaluated by the EI program, were they found eligible for EI services, were they ultimately enrolled in EI services)? 
2. What is the relationship between characteristics of the child (e.g., developmental status) and family (e.g., insurance status) and successful EI referral (i.e., the child has at least been evaluated at the time of the follow up phone call?

3. How do families/caregivers of children referred to EI from the OHSU Developmental Evaluation Clinic (DEC) experience the EI referral process?

a. What roles do EI-referred families see the OHSU DEC and the EI programs playing in their lives?

b. What do EI-referred families experience as facilitators to following through on the referral?

\section{Rationale and Significance}

Participants included in this study consisted of children followed by a high risk infant follow up program serving children whose early medical history place them at increased risk of experiencing developmental delays. The majority of children in this clinic were born LBW and/or premature, a population of particular interest given they are readily identifiable at birth as being at increased risk for experiencing developmental delays, yet are under-enrolled in EI nationally (Barfield et al., 2008; Blasco, Guy, Saxton \& Duvall, 2017; Litt \& Perrin, 2014). Litt and Perrin (2014) point out that LBW children are at particularly high risk of under-utilizing services such as EI since their developmental delays are often subtle and can develop incrementally over time. They found that children born LBW have slightly different EI enrollment patterns than children in the general population in that the majority of LBW children referred to EI were 
referred for LBW/prematurity in the absence of other medical comorbidities. This finding suggests that children born LBW may be less impaired than other children referred from the general population and thus less likely to receive services.

Though there are several research studies (such as those described above) that focus on the characteristics of LBW children and families that are enrolled in EI, there is little information available regarding those children born LBW who are not enrolled in services. Specifically, it is unclear if children not enrolled in EI at any one point in time have not been referred to the program previously, or have been referred in the past but the referral did not result in evaluation and/or services through the program. One study by Tang, Feldman, Huffman, Kagawa, and Gould (2012) indicated children born LBW are under-referred to EI, even when participating in a high risk infant follow up program. However, there was no information available regarding how many of the children referred as part of the study were successfully evaluated/reviewed for eligibility and/or served by the EI program. Ultimately, there is no systematic research investigating how many children with complex medical histories are referred to EI from a high risk infant follow up clinic but are never evaluated by the program. Additionally, there is currently little representation of family perspectives regarding EI as it relates specifically to children born LBW.

This study provides information regarding referral outcomes in one local high risk infant follow up program serving children with complicated medical histories, the majority of whom were born LBW. Reliable information regarding EI enrollment outcomes (rather than anecdotal evidence suggesting they are often not successful) 
gathered from this study will be used to justify use of funds for quality improvement projects targeting creation of a formal EI referral protocol in clinic. This project also answers a call for research and policy to "address gaps in collaboration between healthcare and EI professionals that impede the identification and referral of infants born early who are at risk for developmental delay and disabilities" (Division for Early Childhood, 2017, p. 10).

\section{Hypotheses}

Based on literature review in conjunction with clinical experience, I hypothesized that many of the children referred to EI from DEC will not have been evaluated at the time of the follow up call. Additionally, I hypothesized that a portion of the children evaluated by EI will not be found eligible for services. Previous research looking at rates of EI utilization suggests children born LBW who score lower on developmental testing and have more medical severity indicators (e.g., lower birth weight, longer stay in the Neonatal Intensive Care Unit) are more likely to be enrolled in EI, which I suspected would also be the case in terms of likelihood of being evaluated at the time of follow up call (Atkins et al., 2017; Litt \& Perrin, 2014; Tang et al., 2012).

\section{Definitions of Key Concepts/Organization Descriptions}

Low Birth Weight. Low birth weight is defined in the medical literature as a birth weight less than 2,500 grams. This condition commonly co-occurs with prematurity (i.e., birth prior to 37 weeks gestation) (Jin, 2015). Birth weight can be further classified into very low birth weight (VLBW $, \leq 1,500$ grams) and extremely low birth weight (ELBW, $\leq 1,000$ grams). 
Developmental Delays. This term is used broadly to describe a child's developmental status in regards to meeting basic developmental milestones in the areas of Motor, Cognition, and Language. In Oregon, in order to qualify for services based on having developmental delays a child must be administered a standardized developmental assessment and earn scores that fall more than two standard deviations below the mean in at least one developmental area or 1.5 standard deviations below the mean in two or more areas (OAR 166-500-0020).

Primary Care Physicians. Primary care physicians (PCPs) are medical professionals that are designated as the primary source of routine medical care for an individual. Pediatricians, Family Medicine Providers, Physician's Assistants, and Licensed Nurse Practitioners are common medical providers acting as PCPs for pediatric populations. These professionals who work with pediatric populations provide critical developmental screening services in children and are the primary referral source for EI programs (Hebbeler et al., 2007). These providers may work within large hospital systems, or smaller local outpatient practices. Ideally, regardless of their work setting, providers acting as PCPs for pediatric patients should be following the developmental surveillance and screening procedures outlined by the American Academy of Pediatrics (2006), which includes developmental screening at regular intervals birth-three years of age (i.e., 1, 2, 4, 6, 9, 12, 15, 18, 24, 30, and 36 months). However, this is not always completed, especially in smaller, and/or more rural medical practices serving a wide agerange of patients, as they are often understaffed (Bodenheimer \& Pham, 2010). Of note, these recommended developmental screening timelines (to be conducted as part of 
primary care) are separate from the developmental evaluation timelines determined by individual high risk infant follow up programs.

Part C early intervention programs. Part C Early Intervention (EI) programs are mandated by the federal government and implemented by county and/or regional programs (IDEA, 2004). In Oregon, EI services are provided by one of 19 Education Service Districts (ESDs), organizations that serve one or more counties on behalf of the Oregon Department of Education. According to Oregon law, ESDs were created to “assist school districts and the Department of Education in achieving Oregon's educational goals by providing equitable, high quality, cost-effective and locally responsive educational services at a regional level" (Oregon Revised Statute ORS 334.005). Education Service Districts operate much like school districts, with a board of directors, superintendent, and directors for each branch of the ESD who are responsible for managing particular teams. The EI program that serves children from birth to three years of age is just one of the many programs that are included under the umbrella of services provided by ESDs. The EI department generally includes occupational therapists, early intervention specialists (i.e., EI teachers), speech-language pathologists, physical therapists, autism specialists, and behavior specialists. From birth to three years of age, services are generally provided in the child's home.

High risk infant follow up program. This term generally refers to outpatient clinical programs intended to serve children (usually ages birth-three years of age) with complicated early medical histories that place them at increased risk for developmental delays (including those born LBW and/or premature). These programs are usually 
affiliated with a hospital system and are intended to provide extra developmental surveillance (in addition to the regular developmental screening provided through PCP well child visits). Recommended timelines for follow up vary by clinic, though most include at least three visits in the first three years of life. These programs also help connect families with appropriate resources in their community, including EI programs.

Successful referral. For the purpose of this study, this term will refer to children who have been evaluated for eligibility by the EI program after the referral was placed (as opposed to children who were referred but for some reason were never evaluated to determine if they met eligibility criteria for the program). Though enrollment metrics will also be calculated, success of the referral will considered based on whether or not the child has been evaluated by the EI program at the time of the call. 


\section{Chapter 2: Literature Review}

This study explored EI referral outcomes from a high risk infant follow up program serving children born LBW, investigating both the ultimate referral outcome and the relationship between particular characteristics of the child and/or family and successful EI enrollment. The second, qualitative phase of the study investigated regarding the parent/caregiver experience of the current EI referral procedure, as well as their understanding of the roles of each program and their perspective on what factors facilitate a successful referral. Results from this work will be used to inform a quality improvement project to improve clinical care for children born LBW by improving referral procedures.

This section summarizes the relevant literature on early intervention enrollment, rationalizes conceptualization of low birth weight (LBW) as a chronic health condition, and explores research on the challenges of connecting children born LBW to Early Intervention (EI) services. It also proposes the Chronic Care Model (CCM) as a framework to address gaps in service utilization and explores Ecological Systems Theory (EST) as a theoretical framework supporting use of the CCM, as both CCM and EST emphasize the importance of connections between systems in a child's environment.

\section{Barriers to Successful Early Intervention Enrollment}

Factors predicting early intervention enrollment in the general population.

Though EI programs are intended to support children who are experiencing or at risk for experiencing developmental delays, research suggests that EI programs are serving only about $10 \%$ of children in the general population likely to be eligible for services 
(Rosenberg et al., 2008). One study investigating factors associated with EI enrollment found children with diagnosed medical conditions (e.g., cerebral palsy, visual impairment) conferring categorical eligibility for EI (i.e., diagnoses that result in automatic eligibility) have both the highest enrollment rates and the timeliest entrance into EI services (Bailey, Hebbeler, Scarborough, Spiker, \& Mallik, 2004). The authors noted that children without an established diagnosis who had to evidence developmental delays in order to qualify were enrolled several months (on average) after children with established diagnoses. Furthermore, subsequent research by McManus and Rosenberg (2012) suggests children with more persistent delays are more likely to be served than those with a more dynamic developmental presentation (e.g., a child who scores within the average range on developmental testing initially, then falls behind over time), highlighting the need for regular development surveillance for children deemed at-risk for experiencing developmental delays, including children born LBW.

\section{Factors predicting early intervention enrollment for children born low birth}

weight. Data from the NEILS study showed that while children born LBW consist of about $32 \%$ of the children enrolled in EI nationally; However, EI is only serving a fraction of the population of children born LBW nationally, a fraction which varies widely state to state (Hebbeler et al., 2007). One study conducted in Oregon using 165 children from a clinical dataset (Blasco \& Saxton, 2009) found $71.5 \%$ of infants born LBW who were followed by a high risk infant follow up clinic were not enrolled in EI at the time of their first visit to the program (Atkins et al., 2017). Children were more likely to be enrolled in EI if they had more significant medical risk factors (i.e., lower birth 
weight, younger gestational age, longer NICU stay) and lower scores on developmental testing. Of the 118 children not enrolled in EI at the time of their first visit to the high risk infant follow up program, there was no information available as to why the children were not enrolled, or if they had been referred previously. Additionally, of the 107 participants in the study who lived in Oregon, $42 \%$ would have qualified automatically for EI due to having a condition associated with a high probability of developmental delay (i.e., birth weight $\leq 1200$ grams, intraventricular hemorrhage grade III or higher, Apgar score of $\leq 5$ at five minutes). This is especially worrisome given the conditions listed above are easily recognizable at birth, associated with a high probability of developmental delays, and are conditions conferring categorical EI eligibility, without need to wait to evidence developmental delays on standardized testing.

Additional research completed using the same dataset (Blasco \& Saxton, 2009) investigated EI enrollment across birth weight categories (i.e., LBW $\leq 2,500$ grams, VLBW $\leq 1,500$ grams, ELBW $\leq 1,000$ grams, Blasco et al., 2017). The authors found children born VLBW or ELBW were more likely to be enrolled in EI than children with heavier birth weights. However, the majority of children born VLBW (54.4\%) and ELBW $(61.8 \%)$ were not enrolled in EI, despite the fact that all children born ELBW are considered automatically eligible for EI services in Oregon by having a birth weight $\leq$ 1200 grams. Logistic regression indicated age and birth weight (specifically older children with lower birth weights) were significant predictors of EI attendance ( $\mathrm{F}(2$, $276)=11.674, p<.001)$. Results also indicated that scores on developmental testing (gathered via administration of the Bayley Scales of Infant and Toddler Development $3^{\text {rd }}$ 
Edition, BSID-III, Bayley, 2005) showed significant differences in performance (with lower performance among those attending EI) in the Motor and Language domains between LBW children attending EI as compared to those not enrolled in EI. For the VLBW children, those attending EI had significantly lower scores in the Cognitive and Language domains, but no difference was found in the Motor domain. There were no significant findings on scores from developmental testing across EI attendance groups in the children born ELBW. For a small percentage (about $11 \%$ of the 279 children included in the study) some data were available regarding why the children were not enrolled in EI services; these data were gathered via parent report on an in-take form. Some of the children not receiving services had graduated from the program $(35 \%)$ or their families cited factors such as scheduling (38\%). However, a percentage of the families cited program factors such as never being contacted by the program $(3 \%)$ or not being found eligible for services (29\%) as their reasons for not being enrolled. The authors called for more research to illuminate the reasons for chronic underutilization of EI services among LBW children.

Additional research specifically with children born LBW indicates that those who score lower on developmental testing and have more medical severity indicators (e.g., lower birth weight, younger gestational ages, longer stay in the Neonatal Intensive Care Unit) have consistently shown to be more likely to be enrolled in EI (Atkins et al., 2017; Litt \& Perrin, 2014; Tang et al., 2012). Enrollment in EI and referral rates have also been higher for children born LBW who have public insurance (i.e., Medicaid) than for those who have private insurance plans, a proxy for socio-economic status (Atkins et al., 2017; 
Tang et al., 2012; Wang et al., 2009). One study by Litt and Perrin (2014) looked at a subset of the NEILS longitudinal study participants who were also Neonatal Intensive Care Unit (NICU) graduates. They found that families of children who were non-white, female, came from single parent households, and/or had heavier birth weights reported more effort in initiating EI services. It was unclear from the data collected if differences in referral rates, stigma related to receiving services, or other barriers to accessing services could explain these disparities in service utilization. There was also some question as to how the referral process (from first raised concerns to eligibility evaluations) created additional challenges for families.

The early intervention referral process. When considering challenges in accessing EI services nationwide for children at risk for or experiencing developmental delays, it is important to examine the source of referrals to the program. IDEA (2004) mandates that EI programs and school districts take joint responsibility for identifying and evaluating children with suspected developmental delays or with conditions conferring categorical eligibility for EI. This responsibility includes disseminating materials describing the EI program and providing instructions for requesting an evaluation. As described in Shapiro \& Derrington (2004), there as six distinct steps in the Child Find process: (a) public awareness efforts; (b) identification of a need (by either a parent or professional); (c) EI referral placement; (d) EI program intake process; (e) EI eligibility evaluation; (f) EI enrollment. Though families can self-refer to EI, the majority of EI referrals nationwide originate from medical professionals. In fact, local EI programs rely heavily on primary care physicians to conduct regular developmental screenings as 
part of their well child checks (i.e., regularly scheduled checkups that occur at one week, two weeks, one month, two months, four months, six months, nine months, twelve months, fifteen months, eighteen months, twenty four months, thirty months, and thirty six months of age) in order to identify children who may be eligible for services (American Academy of Pediatrics' Committee on Children with Disabilities, 2001). Despite the referral source, potential points for breakdown in the Child Find process exist at each step. However, according to research centered on following EI referral outcomes for the general population following developmental screening, the shift from referral to EI intake is the least studied aspect of the referral process (Kavanagh, Gerdes, Sell, Jimenez, \& Guevara, 2012).

Given the high responsibility placed on physicians in identifying young children who may have developmental delays, it is important to highlight physicians' perspectives regarding EI referrals. Silverstein et al. (2006) investigated physician practices regarding EI referral via survey. The authors found the majority of physicians surveyed believed that having an established medical diagnosis was important to consider when contemplating a referral to EI, which is concerning given that evidence of developmental delays is also considered for eligibility nationally. Among those physicians who held the belief that an established diagnosis was an important factor, there were lower referral rates for concerns regarding delayed speech for children who did not have an established diagnosis, despite the fact that the most frequently reported reason for EI receipt on the NEILS was speech/communication delays (Hebbeler et al., 2007). 
Early intervention referral outcomes in the general population. Though there has not been systematic investigation of referral outcomes related specifically to children born LBW, there has been some research related to EI referral and evaluation in the general population. For one mixed methods study, Jimenez et al. (2014) conducted a secondary analysis using data from a randomized control trial investigating a PCP-led developmental screening program in four urban practices. The authors found that $21 \%$ of the children screened were flagged as having a developmental concern. Of those children, $58 \%$ were referred to EI and $30 \%$ of those referred were ultimately evaluated by the program. Directly faxing a referral form to EI (rather than just providing families with a phone number) was strongly associated with EI evaluation. Qualitative interviews were conducted with nine pediatricians from the referring sites. The first major theme discovered in the qualitative interviews was that pediatricians felt that their office's procedures related to developmental screening and EI referral were critical for facilitating successful connections to EI. Specifically, they noted that the ability to fax referral directly to EI programs made the likelihood of successful connection much stronger than relying on families to make the first contact with EI (by providing them with a phone number). Second, every pediatrician interviewed noted that parental concern regarding the child's development (or lack thereof) could promote or discourage EI referral, with some pediatricians implementing an accelerated 'wait and see' approach if parents did not cite concerns. Finally, two-thirds of the pediatricians interviewed were concerned that some parents misunderstand one or more of the questions on the screening tool, which could lead to a delay in EI referral. Though this study sheds light on the referral 
procedures (and success rate) from referrals placed by PCPs serving children in the general population, to my knowledge there is no systematic information regarding EI referrals placed from a high risk infant follow up program and no qualitative interview studies focusing on the experiences of families of children at increased risk of experiencing developmental delays.

Another investigation of EI referral outcomes in Massachusetts used linked birth records, discharge information, and EI program data to investigate birth characteristics predicting EI referral, evaluation, and eligibility in the first year of life (Clements, Barfield, Kotelchuck, Lee, \& Wilbur, 2006). Ultimately, about 6-7\% of all live births in Massachusetts were referred to EI within the first year of life. About $88 \%$ of the children referred to EI were evaluated by the program and of the children evaluated by EI $85 \%$ qualified for services. Birth weight less than 1200 grams and birth weight 1200-1499 grams were significant predictors of EI evaluation. Triplets and other higher order multiple births were about seven times as likely to be evaluated as a result of the referral as singletons or twins. The authors noted that $12 \%$ of children referred to EI were not evaluated at a result of the program. They did not have access to information on why children were not evaluated, which was cited as a limitation of the study. Of note, the authors noted that Massachusetts has one of the least restrictive EI eligibility criteria.

\section{Early intervention referral opportunities for children born low birth weight.}

Given that children born LBW are readily identifiable as having an increased likelihood of experiencing developmental delays from birth, there are several opportunities for EI referral. First, children born LBW may be referred to the program at the time of their 
discharge from the NICU. Following discharge, children born LBW may be referred by their PCP, or by a high risk infant follow up program (such as the clinic setting of this study). However, one large cross-sectional observational cohort study investigating EI referral patterns from 66 high risk infant follow up programs across California found that these programs were regularly identifying developmental concerns for LBW whom they did not refer to EI (Tang et al., 2012). Tang et al., (2012) used data from developmental testing or screening results reported from the 66 different follow up clinics to classify children as "low concern" or "high concern" for experiencing developmental delays. The vast majority of the high risk infant follow up programs from the study tested development using the Bayley Scales of Infant and Toddler Development- $3^{\text {rd }}$ edition (71\%), while a smaller percentage used the Capute Scales (20\%), Gesell Developmental Observation-Revised (9\%), or the Mullen Scales of early Learning (1\%). Tang et al. (2012) found 16\% of infants designated as "low concern" were enrolled in EI at the time of their first visit to clinic (between 4 and 8 months of age) and an additional $7 \%$ were referred following their first visit. For the infants characterized as having "high concern" status, $33 \%$ were enrolled in EI at the time of the visit, while an additional $28 \%$ were referred following the visit. Similar referral (and lack of referral) rates were found for children at their second visit to the clinic (between 12-16 months of age). The authors cited lack of information regarding how many of the EI referrals placed were successful as a significant limitation of the study. 


\section{Conceptual Framework}

Low birth weight/prematurity as a chronic health condition. Given that LBW and prematurity have been linked to long-standing executive functioning and academic challenges as well as differences in the white matter tracts in the brain, researchers have proposed conceptualization of LBW as a chronic health condition (Duvall et al., 2015; Lowe, et al., 2014; Travis, Ben-Shachar, Myall, Feldman, 2016). Goodman, Posner, Huang, Parekh, and Koh (2013) explored several definitions of a chronic health condition found in the literature to support their conceptual model for defining and identifying chronic health conditions. Of the definitions put forward, all of them included the following core components: (a) the condition lasts at least one year, (b) the condition causes a functional limitation, and (c) the condition results in need for specialized care. Based on these criteria, LBW/prematurity qualifies as a chronic health condition. The benefit of conceptualizing LBW/prematurity as a chronic health condition is that it allows for exploration of the challenges of connecting LBW children with appropriate developmental supports in their community (chiefly EI), through a public health/service utilization lens. In contrast, when LBW is viewed only as an acute medical concern, rather than a long-term condition with implications across the lifespan, it is easier to miss the subtle developmental challenges that are especially prevalent throughout childhood. Additionally, by viewing LBW as a chronic health condition, rather than an acute challenge that resolves by the time the child is medically stabilized, the role of EI can be more clearly defined to anticipatory guidance (i.e., intervention targeted toward parents 
providing activities that support advancement of developmental skills) and monitoring developmental progress.

\section{Challenges connecting infants born low birth weight with early intervention.}

Research utilizing parent and EI provider focus groups has revealed interesting insights on the challenge of connecting at risk children (such as those born LBW) with EI services in a timely fashion. Little et al. (2015), conducted focus groups that consisted of parents of children born LBW (about 70\% of whom had children currently enrolled in EI), EI employees, and medical providers (e.g., NICU staff, outpatient physicians). They found that both parents and physicians viewed EI as a helpful service, but thematic analysis of the interviews revealed significant gaps in the referral process, service provision, and coordination of services with medical care. The authors identified three core domains representing gaps in the EI system (i.e., missed opportunities for service provision) in successful enrollment and provision of EI services in this population. The first gap is that the child is eligible but the referral is missed/unsuccessful. Reasons cited for this gap included a missed referral opportunity by NICU staff and/or poor communication between the local EI program and the family. The second gap is that the referral is successful, but the family is not interested in/receptive to EI services. Common themes included parents being reluctant to view their child as delayed, wariness of home visits, social concerns (e.g., housing, food security) taking precedence, and parent perception of EI services as not helpful. The final gap scenario identified was that the family is interested in services, but services are unavailable, difficult to coordinate, or unsatisfactory. Reasons cited for this gap included staffing challenges in EI programs, 
delayed service initiation, limited training across disciplines for EI providers, and poor coordination of EI with medical and private interventions. Though many of the challenges associated with this final scenario are internal to the EI program, poor coordination between EI programs and medical systems is of particular importance to this study because it is an area with room for improvement by referring medical institutions.

In order to combat these challenges, Little et al. (2015) suggested implementation of referral protocols in the NICU that included faxing referral forms directly to the local EI program and establishing a system for following up on the status of referrals via phone call. They also encouraged EI programs to create flowcharts detailing EI eligibility requirements and provision of EI contact information to the families directly. Of note, none of the six referring sites participating in the study had a formal protocol for monitoring EI referral outcomes. Furthermore, the authors suggested that the Chronic Care Model (as described by Bodenheimer, Wagner, \& Grumbach, 2002) could provide a conceptual framework for improving referral procedure and EI enrollment outcomes by better integrating community-based services like EI with medical care.

The chronic care model. The Chronic Care Model (CCM) proposes a shift in clinical focus away from acute illnesses to better supporting a patient's more long-term (i.e., chronic) needs. The overarching goal of the model is to make patient-centered and evidenced-based care easier to accomplish by creating networks of support and resources that are easy to draw upon as part of regular care. Part of creating these networks includes strengthening communication between families, medical providers, and communitybased programs, such as EI. The CCM includes six interrelated components: self- 
management support, clinical information systems, delivery system redesign, decision support, health care organization, and community resources (Bodenheimer, Wagner, \& Grumbach, 2002). Though the model was created with chronic illnesses in mind (e.g., diabetes, heart disease), the principles of the model can also be applied to supporting developmental progress in children born LBW. Coleman, Austin, Brach, and Wagner (2009) point out that CCM is not a prescribed method, but rather "a framework within which care delivery organizations translate general ideas for change into specific, often locally distinctive applications" (p. 81). Given that developmental delays are certainly more chronic than acute, the CCM can be applied to this challenge to improve care and coordination between medical organizations and EI programs.

Self-management support. One of the chief tenets of the CCM is helping patients and their families take responsibility for their/their child's health needs (Bodenheimer et al., 2002). In the case of children born LBW, this component of the CCM could be conceptualized to include all the supports available to families to help them understand the risks associated with LBW/prematurity. Self-management support also includes empowering families with tools to track their child's development while also learning to support their child's ongoing developmental progress. In the medical system, selfmanagement skills can be supported by healthcare providers conducting appropriate developmental screenings at each well-child visit, providing parents with materials developed by the American Academy of Pediatrics' Bright Futures program, and recommending appropriate reading and websites to parents (Hagan, Shaw, \& Duncan, 2017). However, another key action a medical provider can take to help parents learn to 
facilitate the development of their child born LBW is referring them to EI. As discussed previously, research has shown that families who participate in EI with their child report that they are more competent in caring for their children, advocating for services, and accessing formal and informal supports than they would have been otherwise (Bailey et al., 2005). Given that children born LBW are at an elevated risk of experiencing developmental delays, connecting families to EI is a critical component of providing selfmanagement support.

Clinical information systems. As discussed in Bodenheimer et al. (2002), computerized information systems can be easily optimized through use of electronic medical record (EMR) systems. Per the Centers for Disease Control and Prevention's National Center for Health Statistics, $78 \%$ of office-based physicians were using an EMR system for date management in 2013 (Hsiao, \& Hing, 2014). One of the clear benefits of using EMRs is the ease with which repositories can be created and automatic reminders set. In their article on the CCM, Bodenheimer et al. (2002) also suggest setting automatic reminders that can be programmed for certain populations (e.g., children born LBW who have been referred to EI) to follow up on referrals and provide extra developmental guidance. Automatization of clinical information systems can help physicians follow best practice guidelines and close follow up loops effectively.

Delivery system redesign and decision support. In order to allow time for more chronic healthcare needs (including screening for developmental delays and connecting families to appropriate resources), the medical practice must be structured in a way that allows for dedicated time to address these concerns, rather than defaulting to 
prioritization of more acute health needs (Bodenheimer et al., 2002). One way in which the American Academy of Pediatrics (AAP) has structured its pediatric care recommendations to dedicate time to developmental concerns is through recommending regular well child visits. As introduced previously, well child visits consist of regularly scheduled appointments (i.e., several within the first few years of life, then annually) and are intended to provide time for physicians to conduct developmental screening, check in with the family regarding the child's overall health, provide scheduled vaccinations, address concerns, and provide anticipatory guidance (AAP's Committee on Children with Disabilities, 2001).

Health care organization. It is impossible to separate implementation of the CCM in a medical practice from the organization's goals and mission. In fact, Bodenheimer et al. (2002) states, "The structure, goals, and values of a provider organization and its relationship with purchasers, insurers, and other providers form the foundation upon which the remaining 4 components of the chronic care model rest"' $(\mathrm{p}$. 1776). In this section, the authors note that to successfully implement the CCM into a health organization, the company's leadership must make a patient's more chronic needs (such as developmental delays in pediatric patients) a priority. Fortunately, the American Academy of Pediatrics (AAP) is very clear on their position regarding the importance of the pediatrician's role in development screening and their responsibility to refer to EI as appropriate. In a paper detailing recommendations regarding developmental surveillance and referral systems, the AAP's Committee on Children with Disabilities note that "IDEA requires physicians to refer children with suspected developmental delays in a 
timely manner to the appropriate early intervention system" (AAP's Committee on Children with Disabilities, 2001). Given the critical role physicians play in identifying children experiencing (or at risk for) developmental delays and referring appropriately, it would be prudent for healthcare organizations serving pediatric populations to prioritize this activity.

Community resources. Perhaps the most critical element of the CCM as it relates to providing innovation in the way LBW/premature care is received and developmental supports given, is the need to provide community linkages (Bodenheimer et al., 2002). For LBW children and their families, an important community linkage is the connection to EI. Currently, providers in Oregon have access to a state-specific universal referral form, though it is unclear how many practices actually use the form. One clear area for improvement would be strengthening the connections between the local EI programs and medical providers. However, Bodenheimer et al., (2002) note that intervention programs are not the only important connections the medical office can help facilitate. Local community centers, infant/toddler daycare programs, libraries, and parks and recreation programs are other key resources that a medical office could help connect families to. Additionally, depending on the severity of developmental delay/disability present, referrals to the local Developmental Disabilities program (i.e., a county-based program providing advocacy services, case coordination, and resources to families with children who meet specific criteria for having a developmental disability) and Social Security Income office (i.e., a federal program providing medical insurance and income 
to eligible children who meet specific criteria for being chronically ill or having a developmental disability) may also be appropriate.

Critiques. Some clinicians and EI providers may argue that many children born LBW and/or premature are doing well (ostensibly), especially given that many of them fall within the average range on standardized testing in the first few years of life. While there is some consideration to be given to arguments related to the relative need for EI services being greater in other populations of children, the predictive value of the standardized assessments commonly used with infants/toddlers is generally poor and may mask qualitative developmental differences, such as asymmetries in movement patterns that may be indicative of underlying neurological issues (Luttikhuizen dos Santos, de Kieviet, Konigs, van Elburg, \& Oosterlaan, 2013). Additionally, researchers have called into question the validity of using conventional assessments to determine EI eligibility for infants and toddlers (Macy, Bagnato, Macy, \& Salaway, 2015). Given these challenges, addressing LBW/prematurity as a chronic health condition requiring communication and collaboration between health systems, EI programs, and families is a reasonable approach.

\section{Theoretical Framework}

Ecological systems theory. The use of CCM as a framework for viewing developmental delays in young children is relevant in that it emphasizes improving the connections among the family, EI programs, and the medical system, three distinct systems whose interactions have a direct impact children and families. A useful theory for exploring the importance of these relationships is Bronfenbrenner's $(1979,1989)$ 
Ecological Systems Theory (EST). This theory describes how multiple, nesting levels of environmental influences shape child and adolescent development. In this model, the child exists in the center, encircled by the microsystem (interactions within the child's immediate environment), included within the mesosystem (connections between microsystems including homes, daycare/intervention centers, and peer groups), existing within the exosystem (third party contexts that the child is not included it but has influence on those within their microsystem), all of which exists within the macrosystem (the social, cultural, and ideological context). Brofenbrenner's EST also includes a temporal dimension (referred to as the chronosystem) that recognizes the effects of changes within the nesting circles on the development of the child. The EST emphasizes that children are influenced not only by their environment, but by the changing relationships between the systems which include the child's influence on the individuals present in the different systems. Later iterations of this theory also describe how these environmental influences (nurture) interact with a person's biologically shaped characteristics (nature) in order to inform development (Brofenbrenner \& Morris, 1998).

Implications and analysis. EST relates to the issue of EI enrollment in children experiencing developmental delays in that it emphasizes the interactions between systems in a child's environment. In this case, EI programs, medical providers, and families all reside within the microsystem, but the mesosystem refers to the connectedness of each component of the child's microsystem. Brofenbrenner (1989) emphasizes that development (conceptualized over time in the chronosystem) is optimized by strong connections between microsystems. Arguably, a strong connection between family 
members and EI is the most critical relationship affecting development in the mesosytem. However, if the child is never connected to EI by their medical system, the responsibility of facilitating development in ages birth to three falls solely on the caregivers. The emphasis on the influence of the connections between systems in a child's environment has lead later scholars, such as Watling Neal and Neal (2013) to revisit EST to create a networked model of "overlapping configuration of interconnected ecological systems" (p. 735). This model clarifies how systems relate to one another and defines the ecological systems in terms of social interaction patterns.

Critiques. Though EST emphasizes the connections between the child, important people in his/her life, and the natural environment, it does not fully account for human development. Shaffer (2005) points out that while EST is conceptualized as a bioecological model, it does not specifically discuss biological contributions to a child's development. Furthermore, it does not explore how children process environmental information or learn from their life experiences/environment. Shaffer (2005) concluded that EST is "best described as a complement rather than a replacement for other developmental theories" (p. 88). Similarly, Johnson (2008) points out that EST provides a relatively linear conceptualization of what is inherently a non-linear process (i.e., child development). She goes on to propose complexity theory as an appropriate complement to EST, especially when being used to inform educational policy. However, given that this study is more related to organizational procedures and structures than policy, I believe EST remains the most appropriate framework for investigating EI referral outcomes for children born LBW who are served in a high risk infant follow up program. 


\section{Discussion}

The CCM provides an excellent framework for investigating EI service utilizations and barriers to successful connection between children born LBW and their local EI program. When LBW/prematurity is conceptualized as a chronic health condition, the CCM provides a structure for analyzing all points for potential breakdown in the EI referral process for these infants at elevated risk of experiencing developmental delays. Similarly, EST's focus on the interconnectedness of the different environments a child experiences and the relationships between key systems in a child's life provides another means of identifying breakdowns in communication. While CCM focuses on the practical areas to assess when evaluating the health system, EST provides a means of conceptualizing the importance of the connections between the health system, the EI program, and the family. When conceptualized through this model, the connection between parents/caregivers and EI is not only critical, but also potentially vulnerable given that it is often mediated by the family's relationship with the medical system (and primary EI referral source). Ultimately, considering the challenge of connecting children born LBW with appropriate EI services using the CCM as a conceptual framework and EST as a theoretical framework appropriately highlights the relationships between the family, medical providers, and local EI programs while providing a means better analyze current referral practices. Though there is some research illuminating potential factors associated with successful EI referral for LBW infants, additional research is needed regarding how LBW children and their families are accessing these critical services and looking into the role of pediatric practices in following up on their referrals. More 
information on parent perspectives on the utilization of EI is critical in illuminating why so few of these high risk, LBW infants are appropriately connected to EI services in their community.

\section{Logic Model}

Ultimately, the goal of this study was to gain information regarding why some referrals are successful and others are not, using EST as a theoretical framework to analyze the layers of influence within a child's life. To address these goals using Bronfenbrenner's $(1979,1989)$ EST as a theoretical framework, I investigated child factors (the center of the model), as well as three key aspects of the microsystem (namely the family, the medical system, and the EI program), with broad implications for the mesosystem (i.e., the relationships among EI programs, families, and the medical system).

I hypothesized that analyzing data that includes child factors (e.g., biological sex, developmental status, health status, etc.) would reveal interesting relationships regarding how likely a child is to be evaluated following referral. Specifically, as seen in previous research, I hypothesized that a child who scores significantly below average on developmental testing, has public insurance, and/or lower birth weight will be more likely to be successfully evaluated by EI (Atkins et al., 2017; Litt \& Perrin, 2014; Tang et al., 2012). In terms of factors at the level of the family, this research analyzed information available from the follow up phone call on why children were not evaluated by the program (i.e., the reason stated by the EI program regarding why the file was closed). Investigation of these child and family factors was critical in addressing the primary 
research questions of the quantitative phase of the project (i.e., to what extent are children referred to EI from a high risk infant follow up program evaluated at the time of a follow up call), which is centered on the mesosystem. Qualitative, semi-structured interviews were used to address the third, qualitative research question (i.e., How do families/caregivers of children referred to EI from the OHSU DEC program experience the EI referral process?). As discussed in Maxwell (2012), a strength of qualitative research methodology is that it can be applied to understand more about the contextual influences surrounding a particular challenge.

Ultimately, this explanatory sequential research design supplements quantitative information from phase one of the study with qualitative data from the interviews to provide a rich exploration of the challenges in connecting children at increased risk of experiencing developmental delays who are followed by a high risk infant follow up clinic with appropriate EI services. In this fashion, this study adds to the literature on service utilization for children born LBW by investigating the issue through the lens of EST, primarily by investigating connections between key stakeholders in the microsystem (i.e., the family, EI, the medical system), using the CCM as a framework to discuss implications for clinical practice.

\section{Review of the Methodological Literature}

Explanatory sequential mixed methods designs generally start with collection and analysis of quantitative data, followed by collection of qualitative data (Merriam \& Tisdell, 2016). The goal of explanatory sequential research is to use qualitative methods to work toward explaining a particular aspect or component of the quantitative findings 
(Creswell, 2015). As discussed in Ivankova, Creswell, and Stick (2006), this research design is "grounded in the fact that neither quantitative nor qualitative methods are sufficient, by themselves, to capture the trends and details of a situation" (p. 3). For this study, the quantitative data were used to investigate and provide a detailed understanding of the overarching problem of practice (i.e., gain information regarding the referral outcomes for children born LBW who are followed in the high risk infant follow up program). The qualitative phase served to illuminate some of the reasons for the problem through semi-structured interviews with key informants related to the problem (i.e., families experiencing the referral and evaluation process). The main advantages of this research design "include straightforwardness and opportunities for the exploration of the quantitative results in more detail" (Ivankova et al., 2006, p. 5). The primary limitation of this design is that data collection and analysis for both types of data is time intensive and not always feasible (Ivankova et al., 2006).

\section{Statistical Analyses}

This section briefly introduces the statistical analyses used in the quantitative phase of this study and the general rationale behind their selection. Further interpretation of why these specific analyses were used for the quantitative phase of the study can be found in chapter three. The data analysis process for the qualitative phase of the study is also detailed in chapter three.

Descriptive statistics. Descriptive statistics are often used to characterize a particular sample by calculating means (i.e., average), medians (i.e., the middle score), modes (i.e., most frequently occurring score), and standard deviations (i.e., a measure 
indicating the variability of the sample) of continuous variables and percentages of categorical variables (Field, 2018). Descriptive statistics provide information regarding the composition of the sample, as well as information on general outcomes.

Inferential statistics. Pearson Chi Square was used to investigate the relationship between key categorical demographic, medical, and developmental variables and EI evaluation status. This statistical analysis is used when independent variables that are categorical in nature and the dependent variable is also categorical (Field, 2018). Independent samples t-tests were used to explore relationships between select continuous demographic, medical, and developmental variables. This analysis is used when the independent variables are continuous and the dependent variable is categorical (Field, 2018).

\section{Summary of the Research Literature and Application to the Study}

In summary, previous research has highlighted the nationwide challenge of how best to refer and serve children born LBW in local EI programs. This issue has been explored in terms of underscoring the under-utilization of EI services by this population of high risk children (Atkins et al., 2017; Hebbeler et al., 2007). There have also been some concrete recommendations put forth by researchers regarding how to address this challenge (e.g., faxing referrals directly to the program rather than simply giving the family a phone number to call, Little et al., 2015). However, to my knowledge there has been very little investigation of how successful any one of these suggestions are in actually increasing the number of LBW children enrolled in EI in particular community. Additionally, there is very little information available in general regarding EI referral 
outcomes for children born LBW from a high risk infant follow up program. There is also very limited information available regarding the perspectives of families with children born LBW in terms of EI referral procedures or outcomes for children born LBW. 


\section{Chapter 3: Methods}

\section{Purpose of the Study}

The purpose of this mixed methods study was to investigate referral outcomes for children born low birth weight (LBW) who were referred to EI from a high risk infant follow up program at a local academic medical center in the Pacific Northwest of the United States. Quantitative data collected for phase one included scores on developmental testing, basic demographic information (including current service utilization), and select medical information. The primary goal of the quantitative phase of this study was to determine the outcomes of referrals placed to local EI programs from a high risk infant follow up program serving children born LBW (i.e., were they ever evaluated, and if so were they enrolled in the program?). A secondary aim was to determine if there are any variables related to the child/family that predicted successful EI enrollment. The qualitative phase of this study investigated the EI referral process from the perspective of the family.

From a quality improvement perspective, the overarching goal of this research project was to identify potential areas for improvement in terms of facilitating successful referrals (and communication in general) between the hospital staff and local EI programs. Ideally, this research helps to identify subsets of LBW individuals who are at increased risk of under enrollment in EI. Though this study is framed around EI referrals from one high risk infant follow up program at an academic medical center in a Pacific Northwest community, this research is intended to help illuminate some of the challenges of connecting families with appropriate services. 


\section{Quantitative Phase Research Methods}

Study Logistics. The quantitative phase of this study was completed as part of a larger study at Oregon Health and Science University (OHSU) investigating developmental outcomes and service utilization of children born LBW who are followed in an outpatient high risk infant follow up program. This site in particular was chosen because it is associated with the highest ranked Neonatology unit in Oregon and provides the most advanced neonatal care in the region (U.S. News, 2018). Though there are about eight other NICU follow up programs in Oregon, DEC is one of the only programs that includes a transdisciplinary team model and provides follow up for children born LBW who are not yet showing evidence of neurological challenges. The research activity of this study was approved through the OHSU Institutional Review Board (IRB \#00006326), with an appropriate reliance agreement with Portland State University in place. The larger dataset includes medical information and service utilization for many children born LBW and seen in the OHSU high risk infant follow up program. However, this study used data specific to this project (i.e., data from EI referral forms and information gleaned from follow up phone call).

While previous studies have been published using different subsections of this dataset (including Atkins et al., 2017 and Blasco et al., 2017), information regarding EI referral outcomes (i.e., collection of EI referral forms and placing follow up calls to EI programs) from the high risk infant follow up program had not been collected for those projects. This study was initiated as a response to findings from Atkins et al. (2017) and 
Blasco et al. (2017) in order to better understand the high risk infant follow up program's role in facilitating successful connections between families of LBW children and local EI programs.

Participants. Participants included 77 children/families referred directly to EI following evaluation at a high risk infant follow up program at OHSU between August, 2012 and November, 2018, the majority of whom $(81 \%)$ were born LBW (i.e., $\leq 2500$ grams) and/or premature (i.e., $<37$ weeks gestation). Of the 15 children who were not born LBW or premature, all 15 had spent time in the NICU ( $\min =2$ days, $\max =51$ days, $M=17$ days). The average birth weight was 2051 grams, though there was quite a bit of variability among the participants $(\min =600 \mathrm{~g}, \max =4,210 \mathrm{~g}, S D=934 \mathrm{~g}$ ). The average chronological age (based on date of birth) at the time of referral was 11.9 months. The average age adjusted for prematurity (i.e., the age a child would have been at the time of the assessment if he/she had been born at 30 weeks gestation) was 10.5 months. Adjusted ages were calculated for all children born prior to 37 weeks gestation, as long as the testing date was prior to their second birthday (chronological age), as is common practice for children born prematurely. $61 \%$ of the participants in this study were male. The average Cognitive composite score was 86 (falling in the low average range), though there was considerable variability on performance $(\min =55, \max =120$, $S D=15)$. The average Language composite score fell in the slightly below average range $(M=82, \min =55, \max =112, S D=13)$ and the average Motor composite score was also in the slightly below average range $(M=82, \min =46, \max =110, S D=13)$. Please refer to Table 1 for more detailed demographic, medical, and developmental information for 
all participants. Patients were included in the study as long as the referral was placed during the study timeframe and the physical EI referral form (filled out and usually already faxed by the clinician) was given to me by the referring provider for follow up. There were four children who had multiple EI referrals placed from DEC during the study timeframe (i.e., three children who were referred twice, one child who was referred three times). In these cases, only the first referral point was included in analyses. OHSU is an academic medical center in which all patient data can be used in research, so long as all data of interest can be collected as part of routine clinical care and an appropriate IRB is in place. Given that all data for this phase of the study was collected in accordance with this rule, there was no formal consenting process observed for these participants. Children would have been excluded from the study if their parents signed a research optout form at the time of their registration as a patient at the hospital, indicating that they were not willing to participate in clinical research (though no exclusions were ultimately made). 
Table 1

Characteristics of Low Birth Weight Children Seen in the High Risk Infant Follow-Up Program

\begin{tabular}{|c|c|c|c|c|c|}
\hline & $n$ & $M /$ Count & Min & Max & $S D$ \\
\hline Sex (male) & 77 & $47(61 \%)$ & & & \\
\hline Birth weight (g) & 77 & 2051 & 600 & 4210 & 938 \\
\hline Gestational age (weeks) & 77 & 33.2 & 23.4 & 41.9 & 4.6 \\
\hline Adjusted age (months) & 77 & 10.5 & 2.9 & 37 & 7.2 \\
\hline Chronological age (months) & 77 & 11.9 & 2.8 & 37 & 7.2 \\
\hline Primary language (English) & 77 & $57(74 \%)$ & & & \\
\hline Ethnicity (Non-Hispanic) & 77 & $46(60 \%)$ & & & \\
\hline Insurance status (public) & 77 & $57(74 \%)$ & & & \\
\hline Maternal age & 71 & 29 & 17 & 44 & 7 \\
\hline Teen mother & 73 & $5(7 \%)$ & & & \\
\hline Days in N/PICU, total & 77 & 41 & 2 & 296 & 46 \\
\hline $\begin{array}{l}\text { Intraventricular hemorrhage, grade } \\
\mathrm{III}+\end{array}$ & 75 & $3(4 \%)$ & & & \\
\hline Apgar score $<5$ at $5 \mathrm{~min}$ & 69 & $10(15 \%)$ & & & \\
\hline Cognitive composite & 76 & 86 & 55 & 120 & 15 \\
\hline Language composite & 75 & 82 & 55 & 112 & 13 \\
\hline Motor composite & 72 & 82 & 46 & 110 & 13 \\
\hline Receptive scaled score & 73 & 6.5 & 1 & 12 & 2.7 \\
\hline Expressive scaled score & 73 & 7.2 & 1 & 12 & 2.5 \\
\hline Fine motor scaled score & 73 & 7.1 & 1 & 12 & 2.4 \\
\hline Gross motor scaled score & 71 & 6.8 & 1 & 13 & 3.1 \\
\hline
\end{tabular}

Note. Count data are presented as $\mathrm{n}(\%)$ unless otherwise indicated. 
High risk infant follow up clinic. Participants consist of patients seen in a particular high risk infant follow up program housed at OHSU in the Child Development and Rehabilitation Center (CDRC), called the Developmental Evaluation Clinic (DEC). The DEC runs on the second and fourth Fridays of each month and serves 16-18 children per clinic day. The majority of the children seen in DEC are referred upon discharge from OHSU's NICU; However, the program also accepts referrals from physicians outside of the hospital. The clinic is intended to follow children who have complex early medical histories, including many children born LBW and/or premature. The goal of the DEC program is to monitor development, address parental concerns (either medical or developmental in nature), provide family education regarding developmental progress, and refer families for additional evaluations and/or community sources as needed. As part of participation in this transdisciplinary clinic, each child was seen by a clinician (e.g., speech-language pathologist, psychologist, special educator or occupational therapist) who performed standardized developmental testing (i.e., BSID-III, Bayley, 2005), and a developmental pediatrician, who took a medical, social, and developmental history and provided a neurodevelopmental evaluation. Children are generally evaluated in clinic around six months of age and then again at one, two, and three years of age. Based on their performance in clinic and parent report, children who the evaluating clinician/physician feel would likely qualify for EI services can be referred at any one of their visits to clinic. 
Procedures. As part of routine clinical care, participants' developmental skills were evaluated using The Bayley Scales of Infant and Toddler Development-Third Edition (BSID-III) at the time of the child's visit to the high risk infant follow up clinic. A referral to EI was suggested to the family by the clinician/physician team seeing the patient if medical history, scores on developmental testing, and/or neurodevelopmental exam suggested the child may qualify for EI services (though only local EI programs determine eligibility). If the child's family was interested in connecting to EI after initial discussion with the clinician/physician, the EI referral form was then signed by a parent and faxed directly to the appropriate EI office (based on the child's county of residence). Ideally, the child is then evaluated for eligibility by the EI program (by meeting with the family and either administering their own testing, or reviewing the referral information to make determinations regarding eligibility).

For the purpose of this study, clinician/physician teams had been asked to give the referral form to me at the end of the clinic day. Phone calls were placed to EI programs several months following referral to gather information regarding referral outcomes and ultimate enrollment. The majority of follow up phone calls were completed by me, with a subset completed by a volunteer research assistant (recruited, selected, trained, and supervised by me through OHSU's Office of Visitors and Volunteers, in accordance with OHSU policy regarding research volunteers). While there was no formal script for the follow up calls, the person making the call shared the patient's name and date of birth with the in-take coordinator for the county EI program and asked (a) if the child was evaluated for eligibility by the program; (b) if the child qualified for services; (c) if the 
child was enrolled in services, and (d) if enrolled, what EI services was the child receiving and with what frequency (in minutes per month). If the child had not been evaluated for eligibility at the time of the phone call, or had been evaluated and qualified but not enrolled in services, the caller asked the EI in-take coordinator for the reason written in the file (e.g., the family did not return the phone call from EI, cancelled the EI appointment, declined services, had moved to another county, etc.) Phone calls were placed to contact EI organizations serving children in 20 counties across Oregon and SW Washington (e.g., Marion, Washington, Multnomah, Polk, Yamhill, Douglas, Linn/Benton, Clark, Klamath, Clackamas, Clatsop, Coos, Columbia).

Instruments and measures. Developmental testing in the high risk infant follow up included administration of the BSID-III (Bayley, 2005), a broad developmental assessment that investigates skills in the domains of Language (receptive and expressive), Motor (gross and fine), and Cognition. Scoring yielded composite scores (mean of 100 and standard deviation of 15) for Language, Motor, and Cognition and scaled scores (mean of 10 and standard deviation of 3) for Receptive Language, Expressive Language, Fine Motor, Gross Motor, and Cognition. Administration of the BSID-III was completed by a trained clinician in accordance with published administration and scoring guidelines. Children born at less than 37 weeks gestation who were less than 24 months of age at the time of the assessment received age corrections for prematurity, as described in the BSID-III administration manual. As noted previously, the BSID-III is very commonly used in high risk infant follow up programs serving children born LBW (Tang et al., 2012). The BSID-III also correlates to similar instruments to a reasonable degree and has 
been shown to be sensitive to performance differences between children born LBW and typically developing, age-matched peers (Bayley, 2005). Please refer to Table 2 for information regarding the reliability of the measure. 
Table 2

Reliability and Stability Coefficients of the Subtests and Composites for All Ages

\begin{tabular}{|c|c|c|c|c|c|c|c|}
\hline \multirow[t]{2}{*}{ Subtest/Composite } & \multirow{2}{*}{$\begin{array}{c}\text { Average } \\
r_{x x}{ }^{a}\end{array}$} & \multicolumn{2}{|c|}{ First Testing } & \multicolumn{2}{|c|}{ Second Testing } & \multirow{2}{*}{$\begin{array}{c}\text { Corrected } \\
r^{a}\end{array}$} & \multirow{2}{*}{$\begin{array}{l}\text { Standard } \\
\text { Difference }\end{array}$} \\
\hline & & $M$ & $S D$ & $M$ & $S D$ & & \\
\hline Cognitive & .91 & 10.0 & 3.0 & 10.9 & 3.0 & 0.81 & 0.30 \\
\hline $\begin{array}{l}\text { Receptive } \\
\text { communication }\end{array}$ & .87 & 10.0 & 2.4 & 10.3 & 2.5 & 0.83 & 0.12 \\
\hline $\begin{array}{l}\text { Expressive } \\
\text { communication }\end{array}$ & .91 & 10.2 & 2.4 & 10.5 & 2.5 & 0.87 & 0.12 \\
\hline Fine motor & .86 & 9.8 & 2.8 & 10.4 & 3.0 & 0.80 & 0.21 \\
\hline Gross motor & .91 & 9.8 & 2.8 & 10.3 & 2.8 & 0.82 & 0.18 \\
\hline $\begin{array}{l}\text { Language } \\
\text { Composite }\end{array}$ & .93 & 100.4 & 12.2 & 102.5 & 12.8 & 0.87 & 0.17 \\
\hline Motor composite & .92 & 98.9 & 14.6 & 104.5 & 14.9 & 0.83 & 0.24 \\
\hline
\end{tabular}

$\boldsymbol{a}$ Average reliability and coefficients were calculated with Fisher's $z$ transformation

$b$ The Standard Difference is the difference of the two test means divided by the square root of the pooled variance, computed using Cohen's Formula

Information regarding current service enrollment (in EI, private services, and/or community health programs) and basic demographic data was collected via parent report on a clinical intake form, or retroactively extracted directly from the medical record (if the form was unavailable). Information regarding what specific developmental concerns were present at the time of referral were collected directly from the universal EI referral form based on which of the areas for concern were checked by the referring provider (e.g., cognitive, gross motor, fine motor, receptive language, expressive language, adaptive skills, hearing, vision, etc.) 
Data collection. Scores on developmental testing in all domains (i.e., receptive language, expressive language, fine motor, gross motor, cognition) were collected as part of administration and scoring of the BSID-III at the time of the visit and later extracted from the child's electronic medical record. As noted above, administration of the BSIDIII was completed by a trained clinician (e.g., special educator, psychologist, speechlanguage pathologist, occupational therapist). Service utilization and demographic information was collected from the intake form mentioned above (completed by a parent/caregiver) or retroactively extracted from the child's medical record, along with select medical variables (e.g., birth weight, age, Apgar scores, days spent in the NICU). Phone calls were placed to EI programs several months following referral to gather information regarding referral outcomes (i.e., determine if the child was evaluated, if they qualified for services, if they were enrolled in services, what services they ultimately received and in the event they were not evaluated the stated reason).

Data storage. Data collected for this study was entered in an IBM SPSS database and stored on a restricted access folder on OHSU's secure hard drive, in accordance with OHSU policy.

\section{Qualitative Phase Research Methods}

As discussed in Miles, Huberman, and Saldaña (2014), one of the strengths of gathering qualitative data is that they center on, "naturally occurring, ordinary events in natural settings" that are locally grounded (i.e., collected in close proximity to the phenomenon of interest, p. 11). Given that this project aims to explore and improve EI referral outcomes for LBW children easily identified as being at increased risk for 
developmental delays, further investigation of the family's experience with the EI referral process is critical. As discussed previously, an explanatory sequential mixed methods design was chosen in particular in order to use qualitative methods to work toward explaining a particular aspect of the quantitative findings (Creswell, 2015). In this case, the quantitative data is used to investigate and provide a detailed understanding of the overarching problem of practice (i.e., gain information regarding the referral outcomes for children born LBW who are followed in a high risk infant follow up program). The qualitative phase of this study is intended to add texture and context to the results found in the quantitative phase by illuminating the family's experiences with the current EI referral procedure through qualitative interviews.

Qualitative interviews are ideally suited to investigating the family experience because it allows for developing detailed descriptions of a process that led to a particular outcome (Weiss, 1994). Semi-structured interviews also allow for integration of different perspectives, as the interview is not bound to follow the exact same interview protocol for each participant, providing more freedom to explore the individual experiences of participants (Weiss, 1994). Ultimately, the qualitative interviews are intended to generate rich information regarding how to improve the EI referral experience for families by including families as key informants and valued stakeholders.

Study Logistics. This phase of the study was completed as part of a larger study at Oregon Health and Science University (OHSU) investigating developmental outcomes and service utilization of children born LBW who are followed in an outpatient high risk infant follow up program. Participants for this phase of the study were selected from the 
sample used in the quantitative phase of the study. The research activity of this phase of the study was submitted as an amendment to the OHSU Institutional Review Board (IRB \#00006326), as the original IRB did not allow for collection of data outside of routine clinical care. This phase of the study also had appropriate reliance agreement with Portland State University in place.

Participants. Potential participants for interviews were identified via purposive sampling and recruited from the families and children referred to EI from the DEC program at OHSU that were identified in phase one of the study. Calls were made to ten families. Ultimately, five parent/caregivers were interviewed for the study, including three parents/caregivers whose children were successfully referred to EI from DEC and two parents/caregivers of children whose EI referrals did not result in EI eligibility evaluation (see Table 3). Pseudonyms were chosen for all participants and some potentially identifying details have been altered to protect their privacy. All participants spoke English as a primary language (though one parent was bilingual in English/Spanish) and were referred to EI from DEC within 18 months of the interview call date. All of the interviewed participants were women. Though I did not inquire directly into their status as working or stay-at-home parents/caregivers, all of the phone participants were reached during the middle of a weekday and were actively caring for their children at the time of the call. I was the clinician who had referred four of the five interview participants to the EI program. One of the participants had been referred by a colleague in the DEC program. Given that the purpose of this research is to gain information to guide changes to the EI referral protocol of a specific high risk infant 
follow up program, these families were uniquely positioned as critical stakeholders to provide information to contextualize the quantitative results and inform quality improvement efforts. A waiver of documentation of consent in place with the IRB allowed interview participants to consent verbally to participate in the study, without written documentation. 


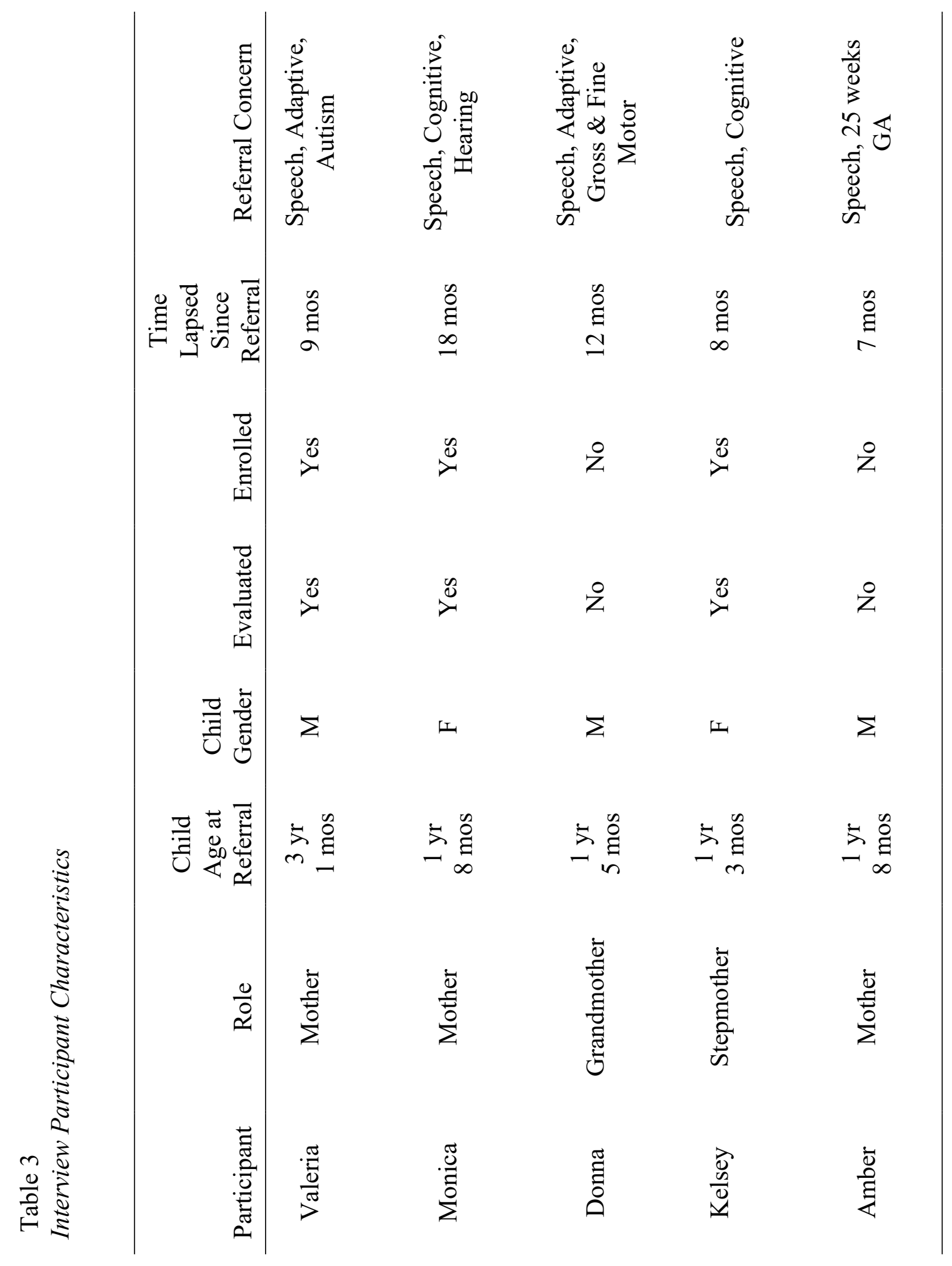


Valeria. I met Valeria (all names are pseudonyms) as part of her son, David's, clinical visit to DEC about nine months prior to calling her on the phone. David had been born about six and half weeks early and staying in the NICU a little over two weeks before coming home. He did not have any major complications in the NICU. Valeria and her family speak both English and Spanish at home, which is located in a suburb just outside a major metropolitan city. David had recently turned three years old at the time of the visit, which represented his third DEC visit. David tested within the low average range for the Cognitive and Motor domains, but was significantly behind in both Expressive and Receptive Language. His social engagement was limited during testing, it was difficult to establish joint attention, and he needed frequent redirection to maintain his participation in the adult-directed tasks of the assessment. I was concerned that he was demonstrating characteristics of autism and he was referred to the CDRC Autism program, in addition to EI. David was evaluated by the EI/Early Childhood Special Education program and enrolled in an ECSE preschool program twice a week, with the services of a speech-language pathologist.

Monica. Ava, Monica's daughter, had the longest amount of time elapsed from the date the referral was placed to the date the phone interview was completed (i.e. 18 months). I evaluated Ava in DEC on her second visit to the clinic, when she was about one and a half years old. I placed her EI referral after she scored average in the Motor section, slightly below average in the Cognitive domain, and significantly below average in Communication. Ava was born at 34 weeks gestation weighing just 1800 grams (slightly under four pounds) and lived in the NICU for a little over two weeks. Ava was 
evaluated promptly by EI and saw a speech-language pathologist in her home for about a year before being discharged due to significant progress in her language. Ava's family speaks English exclusively and lives in a major metropolitan area.

Donna. Donna's grandson, Jayden, was evaluated in DEC by me when he was about one and a half years old (about one year prior to the interview). Jayden was born at $233 / 7$ weeks gestation, representing birth at what is commonly considered the limit of viability in a neonate. He was born at an extremely low birth weight, 700 grams (i.e., 1 pound, 8.6 ounces). He lived in the NICU for the first 24 weeks of his life and experienced many of the medical complications common with extreme prematurity (e.g., intraventricular hemorrhage-grade III, cardiac anomalies, pulmonary dysplasia, inguinal hernia, vocal cord paralysis, feeding/intestinal problems). He was discharged home taking all his nutrition via a nasogastric tube and required supplemental oxygen. $\mathrm{He}$ continues to have cardiac and pulmonary problems requiring regular visits with specialty medical providers. At the clinic visit, Jayden scored in the low average range (for his adjusted age) in the Cognitive domain, but scored in the very significantly delayed range in both the Language and Motor delays. One the day I was conducting phone interviews, I realized that Jayden was being seen for a follow up visit in DEC. I had initially met Donna and Sharon (Donna's daughter, Jayden's mother) at the previous DEC visit. Donna was the only one present at his second visit. Her interview was conducted in person, in the context of his second clinic visit. This was the only interview conducted in person. While Donna is not currently living with Jayden, his siblings, and his mother, she has lived with them on and off in the past. She cares for Jayden regularly and was very 
knowledgeable regarding his life. At the time of the call, Jayden's family was living in a suburb of a metropolitan city, but has been transitioning between houses/counties since returning after a brief move to another state (shortly following the EI referral placement).

Kelsey. I met Kelsey and her step-daughter, Grace, when I evaluated Grace as part of her visit to DEC about eight months ago (when Grace was just over one year old). At that time, Grace had moved about one month prior from a different state (where she had been living with her biological mother). She had moved to live under the care of her father, Steve, and Kelsey. Due to the circumstances of her birth, only imprecise information is available regarding her birth and her first few months of care. She was reportedly born about a month early weighing about five pounds ( $\sim 2,268$ grams) and spent about one month in the NICU. Kelsey and Steve reported concerns about her developmental skills globally and shared that she had been reportedly participating in EI during her previous living situation. Her EI records were not available. Given the uncertainty regarding her gestational age, her developmental scores were calculated without an age corrected (resulting in very significant delays in all areas), and then with a 30 day adjustment (resulting in scores reflecting milder, but still significant developmental delays). She was evaluated promptly following the referral, qualified for services, and was enrolled in home visits with a special educator one time per month.

Amber. Amber and her son, Caleb, were the only interview participants that I did not refer myself (i.e., Caleb was referred by one of my colleagues in the DEC program). I had never met Amber or Caleb prior to the phone call (which was placed about 7 months after the referral). Caleb was born at 25 2/7 weeks gestation weighing only 905 grams 
(i.e., just under two pounds). Caleb's delivery was traumatic and he needed significant intervention to support his respiration immediately following birth. His NICU stay was significant for intraventricular hemorrhage, grade I. He lived in the NICU for just under the first 16 weeks of his life, but was discharged home eating independently and breathing room air. Caleb has been seen twice in the DEC program and was referred to EI when he was about one and half years old. Though he scored within the low average/borderline for his adjusted age, received a relatively large correction for prematurity and was referred due to his birth weight. He lives with his family in a small rural community about two hours away from the DEC clinic site. He was never evaluated by EI following the referral. 
Procedures. One parent/caregiver of a child referred from the high risk infant follow clinic (i.e., the DEC at OHSU) was interviewed regarding their experience with the EI referral process. The semi-structured interview protocol included open-ended questions regarding the parent/caregiver's experience in clinic with the EI referral procedure, as well as the events that followed. For example, (a) Do you remember being contacted by the EI program?; (b) What is your understanding of why [name] was referred to EI?; (c) Did you have any concerns about participating in the EI program?; (d) What is your understanding of why [name] was seen in the DEC clinic? (see appendix B for full interview protocol.) The questions were revised after being piloted through a roleplaying exercise with a colleague who is also a parent. This allowed me to edit my interview questions for clarity, as well as to practice navigating different types of attitudes a parent may bring to the interview. Most interviews were conducted over the phone by me and digitally recorded for later transcription and analysis. One interview was conducted in person and digitally recorded due to the participant having a follow up appointment scheduled in the DEC program on the day of interview phone calls. Participants were not compensated in any way for participation. At the beginning of the phone call, I discussed the purpose of the study, as well as issues related to confidentiality and providing verbal consent. I assured participants that their responses were to be kept confidential, and reminded interview participants that they had the right to decline to answer any of the questions and/or revoke consent at any time. Throughout the interview I attempted to use techniques of mirroring and paraphrasing (as described in Weiss, 1994) to check in with participants regarding my understanding of their responses. 
At the end of the interview, I invited participants to engage in a member checking process, including the opportunity to review the transcript from their interview, as well as an opportunity to review my initial conclusions to verify themes and findings. All participants declined.

Data storage. Transcripts from these phone calls were de-identified and stored in a private folder on OHSU's secure hard drive, in accordance with OHSU policy.

Data Analysis Procedures. The qualitative data was considered in an iterative process including three phases in a cyclical fashion, data condensation, data display, and drawing/verifying conclusions. In order to allow for the iterative process of considering the data and revising interview questions, the data was collected and analyzed concurrently. In order to do this, interview digital recordings were transcribed verbatim and de-identified immediately following the phone call to allow for immersion in the data through a process of reading and re-reading the transcripts. Following immersion in the data, I began coding using the following cycles (described in Miles, Huberman, \& Saldaña, 2014).

First cycle. First cycle coding refers to assigning an initial set of labels to particular chunks of data. The goal of completing first cycle coding is to condense the data while looking for recurring patterns (Miles, Huberman, \& Saldaña, 2014). In this phase, coding includes the following elemental methods of coding: descriptive codes (i.e., a label indicating the basic topic of the passage used to index and categorize), in vivo codes (i.e., words/phrases from the participants own wording indicated with quotation marks), and process codes (i.e., gerunds used to conceptualize actions within 
the data). Affective methods of coding were also used in this cycle to capture the more subjective aspects of the materials. These codes include emotions (i.e., participant perspectives/feelings), values (i.e., attitudes, beliefs, or values of the participants), and evaluation (i.e., codes noting judgements about the significance, worth, or value of something, with subcodes of + or - indicating whether the judgment is positive or negative). Provisional codes based on the literature review and conceptual/theoretical frameworks through a process of deductive coding were created and then revised following completion of phase one of the study (prior to conducting interviews) and throughout the coding process, (see Appendix A for final list of codes). During this first cycle of data analysis I also engaged in jotting to capture my "fleeting and emergent reflections and commentary on issues that emerge during fieldwork" (Miles, Huberman, \& Saldaña, 2014, p. 94). Jottings were made using the comment feature of Microsoft Word and include my notes about the data (e.g., inferences on meaning, personal reactions, thoughts about the interview questions, clarifications etc.)

Second cycle. While first cycle codes are used to summarize data into segments, second cycle coding, or pattern coding, is used to group the first cycle codes into categories/themes, causes/explanations, relationships, and/or constructs (Miles, Huberman, \& Saldaña, 2014). This serves to further condense the data, initiates the data analysis process, helps the researcher create a cognitive map or schema for the process in question, and creates a framework for making comparisons across interview participants (Miles, Huberman, \& Saldaña, 2014). Pattern codes were generated during the second cycle of coding based on themes that emerged in the first cycle. The most salient 
emerging pattern codes were written up as an analytic memo reflecting on the data attempting to synthesize current findings. Given that this was an iterative process, pattern codes were verified/refined with each wave of data collection.

Triangulation of data. One of the strongest strategies for increasing the internal validity of qualitative research findings is through triangulation of the data (Merriam \& Tisdell, 2016). Triangulation refers to the process of supporting findings by showing at least three independent measures supporting the same conclusions (Miles, Huberman, \& Saldaña, 2014). For this study, interview data was triangulated by identifying and analyzing themes across different participants' interviews, as well as across interview questions within a participant. I also analyzed the data for inconsistent or conflicting findings, as these required closer examination of underlying assumptions (Miles, Huberman, \& Saldaña, 2014).

Negotiating entry and gaining trust. As described in Merriam and Tisdell (2016), it is important to establish neutrality regarding the content provided by the interviewee, while also cultivating a respectful rapport. Weiss (1994) frames the relationship between the interviewer and the interviewee as a research partnership, specifying that the interviewer's job is to guide the exploration of the topic while monitoring the material and the interviewee's job is to accept the interviewer's guidance while providing observations. In keeping with this arrangement, I attempted to present the aims of the study (as described previously) in a manner that emphasized the importance of the interviewee's participation in the project. I strove to respond to the parent's experiences/concerns without judgment by cultivating an air of respectful 
curiosity. As a clinician researcher, I concluded the interview (after turning off the recording) by offering follow up as appropriate by asking something along the lines of, "Is there anything I can do to be of service here? Have any concerns come up that you would like to talk about?" At this point, three families had questions regarding follow up recommendations from their visit to clinic, which I answered. One family, who had not successfully connected with EI, requested support in facilitating a second referral, as well as connection with the clinic social worker regarding housing instability. A clinic social worker was contacted to discuss these concerns with the family.

Positionality of the researcher. I am trained as a speech-language pathologist and have worked as a clinician in the DEC clinic at OHSU for the past 7 years. I have previously completed research as part of a larger research project (mentioned above) and I hope to continue this vein of research in the future. I bring several biases to this research study. First, as a contributor to the DEC position statement regarding LBW, I believe that the majority of the children born LBW should be connected (at least in some regard) to their local EI program. I also have strong opinions regarding access to EI services and the importance of developmental surveillance, especially for children born LBW.

The majority of families (4/5) interviewed for the qualitative research phase were families who I had facilitated the EI referral as a clinician in DEC. There was only one caregiver contacted who I had not met before (i.e.., one of my colleagues had seen the child in clinic and facilitated their EI referral). Within this interview context, I had outsider status, but also carried some level of authority within the power dynamic due to my status within the healthcare system. Though I verbally assured the interviewees that 
my interests lay in capturing their experience, some participants may have felt unintended pressure to provide a particular response or some level of guilt/responsibility for the child not successfully connecting with EI. My intent was to gain trust by projecting the motives behind the interviews (i.e., my genuine desire to learn more about their experience in order to better meet their needs), as well as my ongoing commitment to making sure they received appropriate follow up care. Additionally, I attempted to mitigate bias by offering each participant opportunities for member checking at two time points (the transcript itself, and/or findings). However, all participants declined this opportunity. 


\section{Chapter 4: Results}

As discussed previously, the purpose of this explanatory sequential, mixed methods study was to explore EI referral outcomes from a high risk infant follow up program serving children born LBW, as well as the factors associated with successful referral (i.e., the child being evaluated by EI as a result of the referral). An additional aim of the study is to explore the experiences of parents/caregivers of children referred to EI from the high risk infant follow up program to learn more about why some families are successfully connected to EI as a result of the referral, while others are not.

\section{Research Questions}

1. To what extent are the children referred to Early Intervention from the high risk infant follow up clinic connected with their local EI program at the time of follow up phone call (i.e., have they been evaluated by the EI program, were they found eligible for EI services, were they ultimately enrolled in EI services)?

2. What is the relationship between characteristics of the child (e.g., developmental status) and family (e.g., insurance status) and successful EI referral (i.e., the child has at least been evaluated at the time of the follow up phone call?

3. How do families/caregivers of children referred to EI from the OHSU DEC clinic experience the EI referral process?

a. What roles do EI-referred families see the OHSU DEC and the EI programs playing in their lives? 
b. What do EI-referred families experience as facilitators to following through on the referral?

\section{Quantitative Phase Results}

Referral patterns. As seen in Table 4 below, Speech-language was the most common concern indicated on the EI referral form (63\%), followed by Gross Motor (51\%), Fine Motor (33\%), and Cognitive/Problem-Solving concerns (31\%). A smaller fraction of children was referred for Adaptive/Self-Help or Social-Emotional/Behavior (7\% each), with even fewer children referred for Hearing or Vision concerns (4\%). There were 14 children (18\%) whose referral concerns included the "other" category.

Table 4

Referral Concerns for Children Referred to Early Intervention $(n=77)$

\begin{tabular}{lcc}
\hline Concern Area & $n$ & $\%$ \\
\hline Speech/language & 49 & $63 \%$ \\
Adaptive/self-help & 5 & $7 \%$ \\
Cognitive/problem solving & 24 & $31 \%$ \\
Gross motor & 39 & $51 \%$ \\
Fine motor & 25 & $33 \%$ \\
Social-Emotional/behavior & 5 & $7 \%$ \\
Hearing & 3 & $4 \%$ \\
Vision & 3 & $4 \%$ \\
Other & 14 & $18 \%$ \\
\hline
\end{tabular}


Of the 14 children for whom the "other" category of referral concern was specified, five (36\%) were related to prematurity/LBW (e.g., 28 weeks gestation, extremely low birth weight), two (14\%) were related to family needs, two (14\%) were related to hypertonicity (i.e., muscle stiffness), and two (14\%) were related to selfinjurious behaviors/autism. There was one referral specified for each of the following concerns: cardiac issues, attention, and feeding challenges.

\section{Referral outcomes.}

Evaluation status. The primary research question for this study centered on the referral outcomes for children followed in the DEC program (i.e., To what extent are the children referred to Early Intervention from the high risk infant follow up clinic connected with their local EI program at the time of follow up phone call?). Of the 77 referrals placed to EI from DEC during the study timeframe, $48(62 \%)$ of referrals resulted in evaluation through the EI program. Of the 48 children that had been evaluated by EI at the time of the follow up phone call, 33 of them (69\%) are known to have qualified for services, though data on qualification status is missing for one child.

For the 29 children that had not been evaluated by EI at the time of the follow up phone call, over half $(64 \%)$ of the families reportedly did not respond to any of the phone calls placed by the EI program and the referral was closed. Three families scheduled an appointment and then either cancelled (one family) or did not show up for the appointment (two families), while five families (18\%) declined to schedule an evaluation (see Figure 1.) 


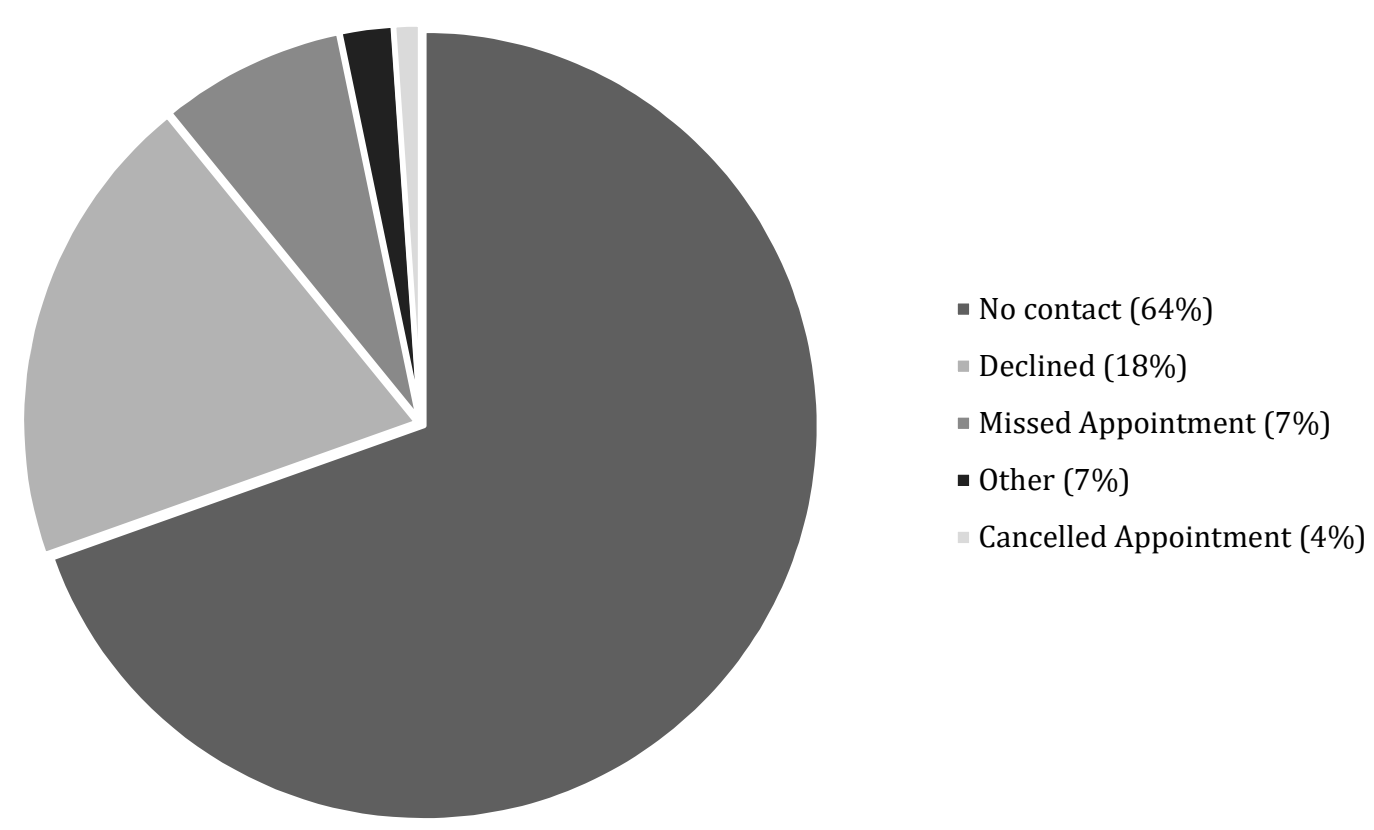

Figure 1. Reported Reason not Evaluated by Early Intervention $(n=28)$

Enrollment status. Of the 32 children who were evaluated and qualified for EI services, $81 \%$ percent were enrolled in services. As seen in Table 5 below, physical therapy (40\%) was the most common service children were enrolled in, followed by speech-language intervention and special education services (both at 28\%), and occupational therapy (24\%). None of the children were enrolled in vision or hearing services through their local ESD. There was only one child who was enrolled in an outpatient rehabilitation service privately (i.e., speech-language intervention) and that child was also enrolled EI services. 
Table 5

Enrolled Services $(n=25)$

\begin{tabular}{lcc}
\hline Service Provider & $n$ & $\%$ \\
\hline Speech-language pathologist & 7 & $28 \%$ \\
Occupational therapist & 6 & $24 \%$ \\
Physical therapist & 10 & $40 \%$ \\
Special educator & 7 & $28 \%$ \\
Vision specialist & 0 & 0 \\
Teacher for the Deaf/hard-of-hearing & 0 & 0 \\
\hline
\end{tabular}

Of the 14 children who were evaluated but reportedly did not qualify for EI services, one child (7\%) would have met categorical eligibility for having a condition associated with high probability of delay and an additional four children theoretically should have qualified based on meeting criteria for developmental delay. Overall, 5/14 children (38\%) who did not qualify should have qualified based on previous testing and/or medical conditions.

Referral acumen. Given the location of the DEC program (Portland, OR), the majority of the patients referred to EI from clinic live in the state of Oregon (83\%), with a smaller percentage living in Washington (17\%). As discussed in Chapter 1, each state has its own criteria for conditions that confer automatic EI eligibility, and its own criteria for what constitutes developmental delay. As a sub-analysis, the referrals for the $24(83 \%)$ of referred children residing in the state of Oregon who were not evaluated by EI following 
the referral were analyzed for the overall referral accuracy (i.e., likelihood that a child would qualify for EI services based on the visit details and referral concerns). Of those 24 children, $4(16.7 \%)$ would have automatically qualified by meeting criteria for at least one categorical eligibility (i.e., having a birth weight of $<1200$ grams, Apgar of $\leq 5$ at five minutes, or IVH grade $\geq 3$, see Table 6 for details).

Table 6

Categorical Eligibility for Oregon Children not Evaluated $(n=24)$

\begin{tabular}{lcc}
\hline Medical Condition & $n$ & $\%$ \\
\hline Intraventricular hemorrhage grade III + & 1 & $4.2 \%$ \\
Apgar $\leq 5$ at five min & 3 & $12.5 \%$ \\
Birth weight $<1200 \mathrm{~g}$ & 2 & $8.3 \%$ \\
Total & 4 & $16.7 \%$ \\
\hline
\end{tabular}

Of the remaining 20 children residing in Oregon who would not have qualified in this manner, eight children (40\%) were likely to have qualified based on meeting Oregon requirements for evidence of developmental delay by scoring 1.5 standard deviations below the mean in two or more developmental domains, and an additional five children (25\%) would have likely qualified by scoring two or more standard deviations below the mean in one developmental domain (OAR 166-500-0020). Overall, of the 24 children living in Oregon who were referred to EI but never evaluated, 17 (71\%) were likely to have qualified based on medical history and/or results from developmental testing. This 
means 7 (29\%) of the referrals placed for children living in Oregon who were never evaluated by the program appear to have been unlikely to result in qualification based on documented developmental skills and medical history.

In terms of the overall appropriateness of the referrals placed to Oregon EI programs from the high risk infant follow up clinic, 15 out of $64(23 \%)$ were likely to meet categorical eligibility for having a medical condition associated with high probability of delay and an additional 28 out of 64 (44\%) were likely to have met criteria for demonstrating evidence of developmental delay. This suggests that $67 \%$ of the total referrals placed appeared to be appropriate based on documented medical history and/or developmental status.

Factors associated with successful EI referral. A secondary aim of this study was to investigate any patterns that may exist between child/family characteristics and outcome of the EI referral. Table 7 shows the breakdown of key medical/demographic variables, as well as performance on developmental testing between children who were evaluated by EI as a result of a referral and those who were not evaluated. Table 7 also displays the results of Pearson chi square tests (completed for all categorical variables) and independent samples t-tests (completed for all continuous variables). As seen in Table 7, the two groups (i.e., children evaluated by EI vs. those not evaluated) were similar in terms of biological sex $\left(\chi^{2}[1]=1.229, p=.268\right)$, with each group having slightly more males that females ( $56 \%$ for those evaluated, $69 \%$ for those not evaluated), which is similar to the total sample ( $61 \%$ males). The two groups were also similar in terms of primary language spoken in the home $\left(\chi^{2}[2]=1.976, p=.372\right)$, with the 
majority being English speakers (i.e., 73\% for those evaluated, 76\% for those not evaluated, $74 \%$ total), as well as insurance status (i.e., with $77 \%$ of evaluated children having public insurance compared to $69 \%$ among the children who had not been evaluated). The groups were also very similar in terms of prevalence of intraventricular hemorrhage $\left(\chi^{2}[3]=.406, p=.268\right)$. Comparatively, there were larger differences between the two groups in terms of ethnicity, with only $52 \%$ of evaluated children identifying as non-Hispanic, as compared to $72 \%$ of those children who were not evaluated; however, this difference was not statistically significant $\left(\chi^{2}[1]=3.107, p=\right.$ $.078)$. 
Table 7

Participant Characteristics by Evaluation Status

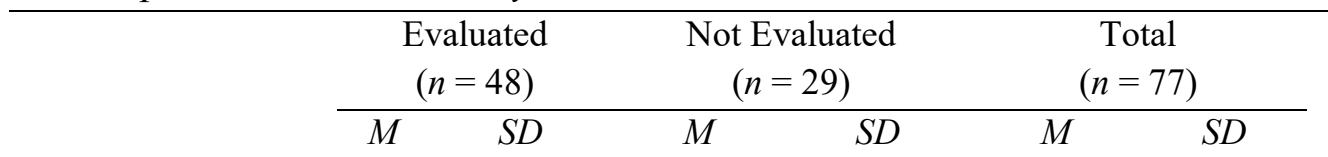

$\operatorname{Sex}[n(\%)]$

$\begin{array}{ccccccc}\text { Male } & 27 & 56 \% & 20 & 69 \% & 47 & 61 \% \\ \text { Female } & 21 & 44 \% & 9 & 31 \% & 30 & 39 \%\end{array}$

Language $[n(\%)]$

$\begin{array}{lcccccc}\text { English } & 35 & 73 \% & 22 & 76 \% & 57 & 74 \% \\ \text { Spanish } & 13 & 27 \% & 6 & 21 \% & 19 & 25 \% \\ \text { Amharic } & & & 1 & 3 \% & 1 & 1 \%\end{array}$

Ethnicity [n(\%)]

$\begin{array}{lllllll}\text { Non-Hispanic } & 25 & 52 \% & 21 & 72 \% & 46 & 60 \% \\ \text { Hispanic } & 23 & 48 \% & 8 & 28 \% & 31 & 40 \%\end{array}$

Insurance $[n(\%)]$

$\begin{array}{ccccccc}\text { Public } & 37 & 77 \% & 20 & 69 \% & 57 & 74 \% \\ \text { Private } & 11 & 23 \% & 9 & 31 \% & 20 & 26 \%\end{array}$

$\begin{array}{llllllll}\text { Birth weight }(\mathrm{g}) & 188 & 841 & 2326 & 1037 & 2051 & 938 & .045^{*}\end{array}$

$\begin{array}{llllllll}\text { Chronological age } & 12 . & 6.8 & 11.0 & 7.8 & 11.9 & 7.2 & .436\end{array}$

$\begin{array}{llllllll}\text { Adjusted age } & 10 & 6.9 & 9.8 & 7.7 & 10.5 & 7.2 & .92\end{array}$

$\begin{array}{lllllll}\text { Gestational age } & 32 . & 4.3 & 34.2 & 5.0 & 33.2 & 4.6\end{array}$

(weeks)

$\begin{array}{llllllll}\text { Total days in NICU } & 38 & 31.7 & 45 & 63 & 41 & 46\end{array}$

Intraventricular hemorrhage $[n(\%)]$

$\begin{array}{llllllll}\text { Grade I } & 3 & 7 \% & 3 & 10 \% & 6 & 8 \% & .939\end{array}$




\begin{tabular}{|c|c|c|c|c|c|c|c|}
\hline Grade II & 2 & $4 \%$ & 1 & $4 \%$ & 3 & $4 \%$ & \\
\hline Grade III & 2 & $4 \%$ & 1 & $4 \%$ & 3 & $4 \%$ & \\
\hline Grade IV & 0 & 0 & 0 & 0 & 0 & 0 & \\
\hline $\begin{array}{l}\text { Apgar score at } 5 \\
\text { min }\end{array}$ & 7.2 & 2.0 & 7.8 & 1.9 & 7.4 & 1.9 & .463 \\
\hline Maternal age & 30 & 7.5 & 28 & 6.6 & 29 & 7 & .274 \\
\hline $\begin{array}{l}\text { Cognitive } \\
\text { composite }\end{array}$ & 85 & 15.7 & 86 & 14.6 & 86 & 15 & .830 \\
\hline $\begin{array}{l}\text { Language } \\
\text { composite }\end{array}$ & 82 & 12.1 & 82 & 13.4 & 82 & 13 & .872 \\
\hline Motor composite & 84 & 11.6 & 78 & 15.2 & 82 & 13 & .093 \\
\hline $\begin{array}{l}\text { Receptive scaled } \\
\text { score }\end{array}$ & 6.6 & 2.6 & 6.4 & 2.9 & 6.5 & 2.7 & .751 \\
\hline $\begin{array}{l}\text { Expressive scaled } \\
\text { score }\end{array}$ & 7.2 & 2.3 & 7.1 & 2.7 & 7.2 & 2.5 & .829 \\
\hline $\begin{array}{l}\text { Fine motor scaled } \\
\text { score }\end{array}$ & 7.4 & 2.1 & 6.5 & 2.8 & 7.1 & 2.4 & .154 \\
\hline $\begin{array}{l}\text { Gross motor scaled } \\
\text { score }\end{array}$ & 7.1 & 2.6 & 6.3 & 3.7 & 6.8 & 3.1 & .326 \\
\hline
\end{tabular}

Note: $p$ values reported on chi square test for categorical variables, independent t-test for continuous variables, *indicates $p<.05$

Both groups were also similar in terms of average chronological age at the time of referral $\left(t_{[75]}=-.784, p=.436\right)$, adjusted age at the time of referral $\left(t_{[75]}=-.691, p=\right.$ $.492)$, Apgar score at 5 minutes $\left(t_{[75]}=-.737, p=.463\right)$, maternal age at birth $\left(t_{[69]}=-\right.$ $1.104, p=.274)$, and total numbers of days spent in the $\operatorname{NICU}\left(t_{[36.831]}=.556, p=.582\right)$. However, there was more variability in days spent in the NICU among the children who were not evaluated at the time of referral $(S D=63)$ as compared to those children that were evaluated $(S D=32)$. Additionally, the average birth weight of children not evaluated was higher and had more variability $(M=2326, S D=1037)$ as compared to the 
average birth weight of children who were evaluated $(M=1885, S D=841)$, a difference which was statistically significant $\left(t_{[75]}=2.0, p=.045\right)$.

In terms of developmental performance on the BSID-III, there were no significant differences between the two groups in terms of cognitive composite score $\left(t_{[74]}=.216, p\right.$ $=.830)$, language composite score $\left(t_{[73]}=-.162, p=.872\right)$, receptive scaled score $\left(t_{[71]}=\right.$ $-.319, p=.751)$ or expressive scaled score $\left(t_{[71]}=-.216, p=.829\right)$. There was slightly more variability between groups in terms of the motor domain. The average motor composite score was lower and more variable among those children who were not evaluated $(M=78, S D=15.2)$ as compared to evaluated children $(M=84, S D=11.6)$, but this difference was not statistically significant $\left(t_{[70]}=-1.074, p=.093\right)$. Gross motor scaled scores were also lower and more variable among those children not evaluated $(M=$ $6.3, S D=3.7)$ as compared to evaluated children $(M=7.1, S D=2.6)$, though this difference was not statistically significant $\left(t_{[41.383]}=-.994, p=.326\right)$. Similarly, fine motor scaled scores were lower and more variable among those children not evaluated $(M$ $=6.5, S D=2.8)$ as compared to evaluated children $(M=7.4, S D=2.10$, though again this difference was not statistically significant $\left(t_{[71]}=-1.439, p=.154\right)$. 
Referral outcomes by birth weight category. As seen in Figure 2 below, there were some differences between referral outcomes across birth weight category. The highest percentage of children were evaluated in the very low birth weight category (83\%), followed by the extremely low birth weight category (71\%) and then the low birth weight category (66\%). There was the lowest percentage of successful EI referrals among the non-low birth weight cohort (45\%). This general pattern of higher percentages of successful EI referrals for the lower birth weight categories is consistent with expectations, given that these are often the most medically complex children. However, these differences in referral outcome across birth weight categories were investigated through chi-square analysis and were not statistically significant $\left(\chi^{2}[3]=4.460, p=\right.$ $.216)$.

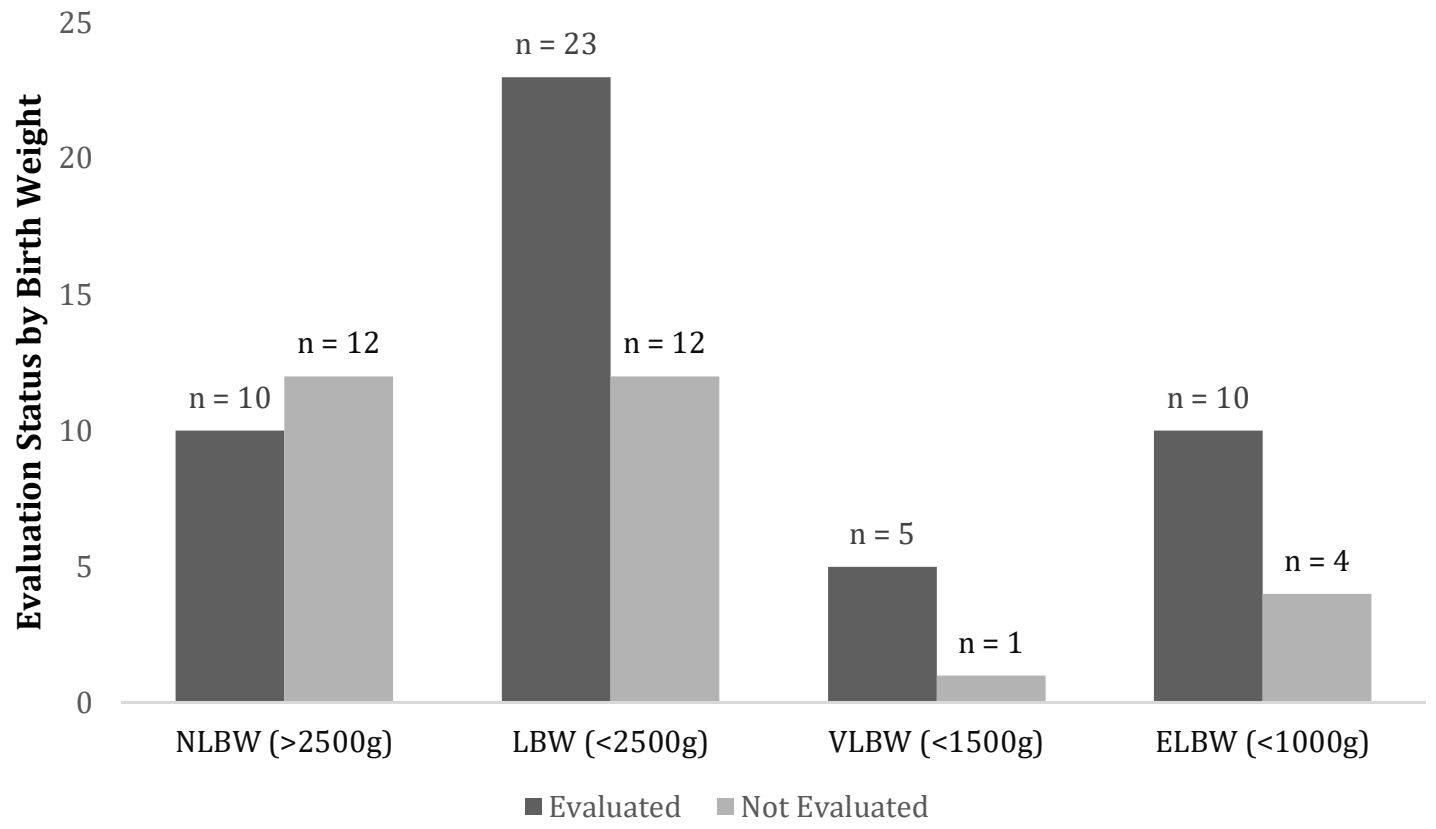

Figure 2. Evaluation Status by Birth Weight Category 
Ultimately, the only statistically significant medical, demographic or developmental factor that appears to have a systematic relationship with EI referral success (i.e., being evaluated as a result of referral) is birth weight $\left(t_{[75]}=2.0, p=.045\right)$.

Relationships among variables. A Pearson correlation coefficient was calculated to investigate the relationships among medical and developmental variables, paired with visual analysis of the associated scatterplots. As seen in Table 8 below, there was a perfect positive correlation between BSID-III Cognitive Scaled Score and the BSID-III Cognitive Composite Score $(r=1.0, n=74)$, which is expected given that both are calculated based on the Cognitive raw score. There was a very strong positive correlation between birth weight and gestational $(r=.893, n=77)$, as well as chronological age and adjusted age $(r=.985, n=77)$. The strength of these pairings matched expectations, given that children with lower gestational ages are expected to have lower birth weights proportionally and adjusted ages are linked to chronological ages. There was a strong negative correlation between number of days spent in the NICU and birth weight $(r=-.600, n=77)$ and number of days spent in the NICU and gestational age ( $r=-.708, n=77)$. Visual analysis of the associated scatterplots confirms that these relationships are linear in nature, indicating that children of smaller birth weights and younger gestational ages tend to have more medical complexity and spend a greater number of days in the NICU. In terms of developmental testing measures, there was a very strong positive correlation between Gross Motor scaled score and Motor composite $(r=.840, n=70)$ and a strong positive correlation between Fine Motor scaled score and Motor composite score $(r=.737, n=70)$. Visual analysis of the scatterplot 
shows these relationships are also linear in nature, which is expected given that the fine and gross motor scaled scores are used to compute the composite score. There were identical, moderately positive correlations between the Cognitive scaled and composite scores when compared to the Receptive Language scaled score $(r=.403, n=73)$ and the Fine Motor scaled score $(r=.527, n=73)$. These correlations are consistent with expectations given the Cognitive subtest requires the ability to follow verbal instructions and that many of the items require manipulating small objects (a fine motor task). There were very similar, moderately positive correlations between the Cognitive composite and Motor composite $(r=.548, n=70)$ and Cognitive scaled score and Motor composite $(r=$ $.556, n=72$ ). In terms of the language items, there was a very strong positive correlation between Receptive scaled score and the Language composite $(r=.851, n=73)$ and Expressive scaled score and Language composite $(r=.820, n=73)$, which is consistent with expectations given that the Expressive and Receptive scales scores are used to generate the Language composite score. There was a moderately positive correlation between Receptive scaled score and both the Fine Motor scaled score $(r=.414, n=72)$ and the Motor composite score $(r=.420, n=69)$. There was a very similar moderately positive correlation between the Language composite and both the Fine Motor scaled score $(r=.408, n=72)$ and the Motor composite score $(r=.435, n=71)$. As seen below in Table 8, all other correlations were weak or very weak. 


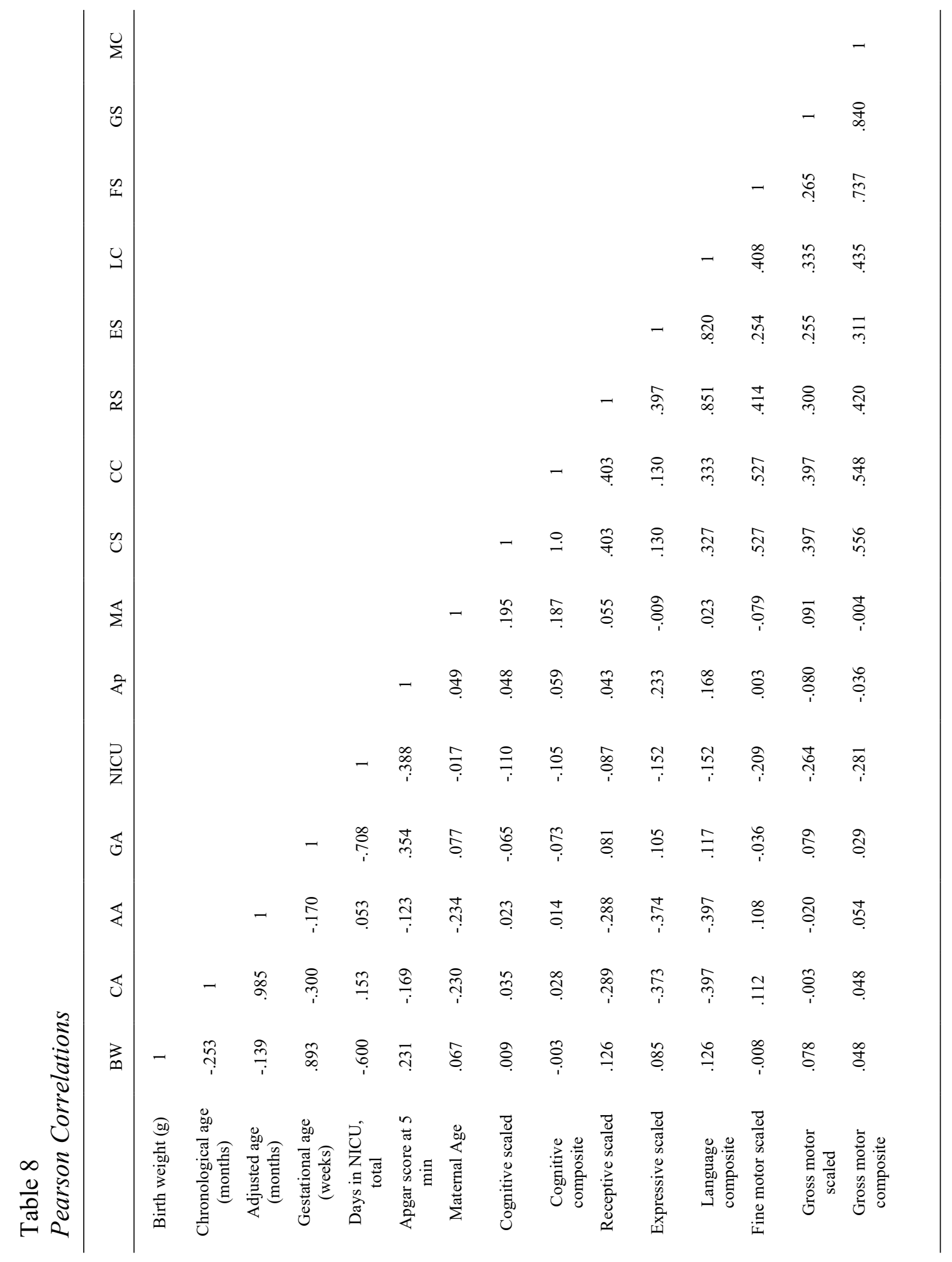


Limitations. This phase of the study was limited by a relatively small sample size, particularly when considering investigation to identify potential predictors of EI evaluation. Given that there are a relatively small number of referrals placed each year (related to the fact that some of the children seen in DEC are already enrolled in EI at the time of the visit, while others are unlikely to meet eligibility criteria), it took several years of data collection to gather these 77 referrals. Additionally, the participants in this study represent EI referrals from one high risk infant follow up clinic in the Pacific Northwest, which limits generalizability, especially considering that different states have differing eligibility criteria. Another limitation is the lack of information regarding whether or not a child had previously been referred to EI. Given that the vast majority of participants spent time in the NICU, it is likely that many of these participants had been referred to EI previously. In fact, there were four children who had multiple referrals placed during the study timeframe (i.e., three children who were referred twice, one who was referred three times). More information is needed to determine if these participants may have been less likely to successfully connect to EI due to already having had difficulty connecting to the program. As discussed in the final chapter, research looking at this first possible referral point is necessary in order to better characterize the outcomes of EI referrals for this population of high risk infants.

\section{Qualitative Phase Results}

The qualitative interviews and the process of conducting them provided rich information regarding the experiences of five of the families who experienced the process of being referred to EI from the DEC program. I identified several key themes through 
analysis of the data and consideration of my experience of conducting the interviews with each participant. The most salient themes are explored here following the lines of inquiry established as the substantive frame of the interview (Weiss, 1994): (a) experience of the referral process; (b) parent/caregiver reaction to the referral; (c) understanding of DEC and EI roles; and (d) factors influencing referral outcome. The majority of identified themes were consistent across research participants, though the level of detail provided in the response varied across participants. The many direct quotes taken from the transcripts below are intended to highlight the voices of the participants of the study and generally represent the most detailed responses consistent with that particular theme. Ultimately, this phase of the study provided valuable insights into why some families do not successfully connect with EI.

Referral process. One consistent theme across the participants was the pride families expressed regarding the amount of developmental progress their children had made since the time of the referral (a time period ranging from 7-18 months, depending on the participant). Two of the three families whose children had been enrolled in EI shared updates of their child's progress in terms of gains since starting EI services. Grace's stepmother (again, all names are pseudonyms), Kelsey, shared that Grace was doing "Great! She talks now—she communicates." Kelsey went on to share that "when we first started she really didn't talk at all. She didn't communicate at all.” The caregivers of both of the children who had not been evaluated by EI as a result of the referral also communicated pride at their child's progress. Donna, Jayden's grandmother shared that, "To me, everything he does at home is wonderful because he's accomplishing things." 
However, Donna also acknowledged that she still felt like he needed help for his global developmental delays, going on to share, "I still get concerned because he walks like a drunken sailor." One striking difference between the two children who were not evaluated by EI at the time of the referral is the current level of developmental concern. Jayden continues to present with global developmental delays identified during his first visit, while Caleb's mother, Amber, reported her concern regarding his mild speechlanguage delay has resolved since the referral was placed. She shared he was now "doing great" and that he had started talking more immediately after the referral was placed.

All of the participants also shared that they understood the reason for referral, with most making references to their child's developmental delays at the time of the referral. When asked about her understanding of the reason for referral, Monica replied, "I remember that she wasn't talking as much as I thought she should be or her dad thought that she should be." Kelsey shared that at the time of the referral Grace, "wasn't walking and she didn’t talk." Similarly, Amber noted that Caleb "wasn’t exactly up to where he should be." All of the participants made references at some point during the interview to speech-language delays at the time of the referral, which was the only referral concern all of the children in this phase of the study had in common. Overall, parent report regarding the reason for the referral was accurate, based on referral concerns indicated on each child's EI referral form (see Table 3 in Chapter Three). Another key theme across participants was the framing of the child's developmental challenges as one consideration in relation to the strengths of the child. 
When asked to report on the reason for referral two of the parents/caregivers were quick to include references to other ways the child was thriving. Monica shared, I remember that she wasn't talking as much as I thought she should be or her dad thought that she should be, and uh um, you know, she just, she's very smart you know. She can count to you know five to ten and, you know, things like that, but it's like was more personal interaction in using her words like engaging with other people and you know things like that.

Other participants shared similar sentiments, framing their child's developmental challenges in the context of their unique strength areas. Kelsey shared, "She wasn't where she needed to be or where - or where she was supposed to be for her age, I should say. And um, even though she's a really freakin smart kid." She went on to specify that Grace is "secretly smart." Donna framed Jayden's task persistence as a clear strength, sharing that he is good about "trying to accomplish what he is after, he doesn't give up easily."

Reaction to the referral. The most consistent theme across this line of inquiry was that participants experienced some level of concern/worry about the developmental skills of their child, but all but one interview participant shared experiencing some measure of anticipatory excitement at the time of the referral, specifically at the prospect of connecting to EI services. Kelsey, whose step-daughter Grace had been receiving EI supports previously (when she was living with her mother in a different state) shared, "I was happy she was getting the help that she needed." Donna shared, 
Oh, I think we both thought it was good. Because especially because she had gone through that before with one so it wasn't a totally strange scenario for her, ya know, she knew that they could do things that and show her how to do things better than maybe what we were trying to do.

When asked how she felt about the EI referral being placed, Amber replied, "It doesn't bother me." When asked directly if she thought Caleb needed to be in EI she shared, "At the time yes, but after that he kinda just started talking even more on his own. So I wasn't really worried anymore." Amber's case was unique in that she was the only parent who reported feeling an initial need for the service that did not persist due to reported developmental progress immediately following the referral. When asked if they had any concerns about the EI referral being placed at the time of the clinical visit, none of the participants reported having any concerns. However, Kelsey replied, "I didn't really have any concerns. I was just... I was unsure of what to do." At this point in the interview, it was unclear whether Kelsey meant that she was unsure of what she could be doing at home to support Grace's development, or unsure what the next steps were after the referral was placed (i.e., if she was supposed to follow up on the referral in some way).

Understanding of roles. Four out of the five interview participants were able to clearly articulate the reason their child had been followed as part of the DEC program. Amber communicated this idea the most succinctly by stating, "Cause he was born so early and preemies usually have a harder time with developmental delays." She did not elaborate on this thought, and it is unclear how she relates this information to Caleb's development in particular. All families made some kind of reference to being seen in the 
DEC program for tracking developmental progress over time. All participants communicated understanding the role of EI as being related to providing training and resources to support families in encouraging developmental progress. Kelsey shared, My understanding is to help them, what's the-what's the, like if they're delayed like motor skills, to help them get where they need to be in the motor skills or speech or like help them develop those skills that they need to be where they're supposed to be for their age.

Similarly, Monica shared that in her experience EI staff, "provide me with the tools and resources and things like that to help catch her up on what she is behind on." Interestingly, Valeria (who had a child currently enrolled in EI), seemed to have some initial confusion regarding the DEC program role, as compared to EI. It was unclear if this perceived confusion was related to a language barrier (English was reported as her second language), if she was confusing the labels for the two clinics (DEC vs. EI), or if the relationship between these programs was not clear. My impression from the interview is that the roles of each clinic were unclear to her and that she may have though the two agencies were directly linked. However, when asked specifically what EI may help a family with she provided a detailed account of the services her child was receiving.

Of the two parents/caregivers whose children were not evaluated as a result of the referral (and thus not enrolled in EI), one of them (Amber) did not remember being contacted by the EI program or report understanding the purpose of the EI evaluation. Results from the quantitative study indicate that she was contacted, but did not return the EI phone call. Amber initially stated that she was unsure of EI's role, though when 
prompted to guess what EI might help a family with she accurately reported, "I'm guessing helping them learn maybe if they have issues with walking or talking, eating, that kind of thing." Donna (Jayden's grandmother) shared that though Jayden was neither evaluated nor enrolled in EI following his referral from clinic, she was familiar with the program because Jayden's older sister had participated in EI when she was younger. She communicated a very thorough understanding of what types of services EI provides, first describing the behavioral services Jayden's older sister had received when she participated in the program and going on to add,

I would think they would intervene with any of that kind of thing. Whether it's hearing or walking or talking or, ya know, reading. Whatever it takes to get them to where they can be with everybody else their age, ya know?

The overall perception from the families regarding the role of EI was accurate in that they described that EI would help children who were experiencing developmental delays, in whatever area they needed support.

As described in chapter three, all three of the participants whose children had been evaluated by EI were ultimately enrolled in the program. Two of them were still receiving services at the time of the interviews (Grace via home visits with an EI provider, David via an Early Childhood Special Education preschool program). Monica's daughter (Ava) had been discharged from EI at the time of the interview due to meeting all of her goals in the 18 months that had passed since she was referred. All three of the participants with children who had been successfully connected with EI communicated gratitude for the referral and consistently positive reviews of the EI program. Valeria 
expressed that she saw significant gains in David's development, despite what she considered a limited amount of time spent in the program each week. She stated, He's showing a lot of improvements since he started going to the EI and you know even me talking to his dad, you know we talked about it because he only goes you know, twice a week for two hours and he's already shown a lot of improvement. Monica reported positive effects from parent coaching through EI, sharing, After we left the appointment then we started seeing the speech pathologist started coming over and working with her and we would play games and just do different activities and like try and get her to use her words more and just lots of repetition, lots of, you know, trying to encourage her to say the words instead of me saying it for her or just assuming what she wants and you know things like that. Giving her like a bunch of different choices and, you know, having her tell me which choice she wants and you know being more verbal about things. But, so yeah, she picked up on things really quickly so like as soon as we set a task for her like she would complete it within that week and then we could move on to the next one.

Monica also described how Ava's referral to EI had a cascading effect in their family, noting that Ava's older brother was also evaluated and served through the program. The speech-language pathologist serving Ava ended up coming for an hour at a time, seeing Ava for the first 30 minutes and her brother for the second half of the session. Two participants noted how quickly the EI program called them following referral. Kelsey shared, 
It was like not even a week later I got a call back and you guys were like well it might take a little bit of time because they're really busy or what not. But yeah, it was like less than a week I got a phone call.

The fact that Kelsey mentioned how quickly EI had gotten back to her following the referral was notable because as a clinician referred families have reported it taking several weeks for the EI program to call. In response to that information, I had been giving families the EI phone number after placing the referral and encouraging them to call the program directly to follow up if they don't hear back within a few weeks. Ultimately, a prominent theme from the interviews was that all of the families who had been enrolled in EI as a result of the referral or had prior experience with the EI program with a different child reported a positive experience with the program. None of the participants I interviewed shared any negative experiences with EI.

Factors influencing referral outcome. The parents/caregivers interviewed in this study shared many insights into why a child may or may not be evaluated as a result of the referral. For example, in every interview, participants highlighted the challenges brought about by competing priorities, such as caring for small children, coordinating care (e.g., scheduling medical follow up visits, navigating insurance coverage options for healthcare and intervention, scheduling intervention sessions), navigating family logistics (e.g., transportation, childcare arrangements) and managing their own health concerns. This was evident not only in the content of the interviews, but also in the overall experience of interviewing these women. All four of the phone interviews were punctuated by interruptions from the participant's children, most notably the interviews 
with Monica and Amber, as they each paused the interview at least twice to respond to their children. Amber had to pause our conversation to physically and verbally redirect Caleb's toddler-age sister from walking into the road. Two participants described how their own health challenges had been affecting their ability to care for their children/grandchild physically and/or to remember details of the recent past. At the very beginning of the interview, when I asked Monica to share what she remembered of the feedback session from the DEC visit she casually replied, "Well, ah gosh bear with me, my memory is not the greatest. I recently started [significant infusion-based medical treatment] here lately so my memory isn't wonderful.” Based on my notes and memos from the interview, the transcripts, and the context of a child's early history provided by chart review, I identified the following salient facilitating factors and barriers to access.

Facilitating factors. The most consistent message from families regarding why some families end up connecting their child to EI during the interviews was related to the general attitude of the parent related to the reason for referral. Many of the participants noted the need for a strong rationale at the time of the referral. This idea that in order to follow through with EI parents need to buy-in to both the reason for the referral and the potential benefit of EI services carried through to their ideas regarding improvement. If evaluation results did not match the concern level of the parent the interview participants shared they felt there would be little follow through. For example, Amber shared that families have to "recognize the need for it." She went on to say that families may be inclined to follow through on the EI referral if they think they will get "something that maybe the intervention can provide that they can't." As discussed previously, of the two 
interview participants whose children had not been evaluated, Amber was unique in that she initially saw the need for the EI referral, but her concerns resolved shortly after the referral was placed. She speculated that families may not be inclined to follow through on the EI referral if the results from developmental testing and the clinician's concern level exceeded the family's level of concern. However, Jayden's situation was different in that his caregivers did report wanting Jayden to be connected to EI and continued to recognize the need for intervention services. Though this was not her particular experience regarding why her child was not evaluated, Donna speculated that most families need to understand the potential benefits of EI, both at the time of referral and in order to continue participating in the program. She shared that many families may need to see results from participating in the EI program in order to maintain participation, stating, Well, if you show me that you can do something to make him talk and interact with other people and stuff, I'm all for it. As long as you can convince that person that what you're doing is going to help them and they can see the help, you know? It's-you've got to see something from what you're doing.

It was unclear if Donna felt like the DEC program could be making a stronger case for a child's need for intervention, or if she felt the EI program needed to be held accountable to demonstrating immediate progress in intervention.

Barriers. As I alluded to earlier, my conversations with each family illuminated the many different responsibilities and challenges that each of these parents/caregivers was facing at the time of the call. However, my experience interviewing Donna as part of Jayden's clinic visit was the most revealing in terms of how many different stressors 
some families served by DEC face. Donna noted that shortly after the EI referral was placed, Sharon moved out of state with Jayden and her other children. The following is an excerpt from the transcript of Donna's interview:

KRISTI: Do you remember [Sharon] ever mentioning being called by Early Intervention after that? Or them trying to set up with her?

DONNA: She may have. I know that she didn't get good cell reception where she was living. Half the time she didn't know she even had phone calls.

KRISTI: When she lived in [state she moved to shortly after the referral]? Or when...

DONNA: No, she lived in [suburb of a major metropolitan area in the Pacific Northwest] at the time. And now she had to go outside of the house to even get a place where she could use the phone.

KRISTI: So, she missed a lot of phone calls?

DONNA: She missed a lot of calls. She would try to call back, you know, there was a lot of not being able to connect not just with this but with all of her doctors. I mean, we had tons of doctors going for him back then. And lots of visits coming up here.

According to Donna, after the move Sharon found "everything was so much more difficult" in her new state. Sharon reportedly had difficulty establishing basic support services, such as medical care and food stamps. A consistent theme across this interview was Sharon "not being able to connect" with services in her new state. Donna was quick to point out that Sharon wanted Jayden to be in EI, but that the "timing was off." Sharon 
and her family moved back to the Pacific Northwest five months prior to the interview after about one month out of state. However, Donna shared that Sharon has had difficulty securing housing for her family since moving back and was living with friends. When this information was shared, I paused the interview in order to connect Donna with our clinic social worker, who performed a needs assessment with Donna at the end of the clinic visit. The social worker also agreed to contact Jayden's mother (Sharon) directly in order to facilitate a new referral to EI. Donna could not sign the referral form, since it acts as a release of information and can only be signed by a parent or legal guardian.

Donna provided the above information about her family situation very early in the interview. Later, when asked directly why she though some families had difficulty connecting with EI services, Donna speculated that some families may have a strong sense of privacy, expressed as the idea that "our business is our business, you don't share it." She went on to conjecture that some families may experience shame about their living situation or not "want their friends to know" their child needs help. Donna also speculated that some families may have, "convinced themselves that there's not a problem." She shared one of her own experiences as a mother:

I had one with a lazy eye that I couldn't see, you know? And I saw her every day. It took a long time for me to realize that she did, and then we worked with the patches and everything. But when they're your own kids, you want to keep thinking that they're normal.

The idea that some families may not want to recognize a need for developmental support was alluded to in other interviews, but not stated as directly as Donna did (above). A 
reluctance to view their child as needing intervention may be a significant factor in some cases, as results from phase one of this study show that families not returning the EI phone call is a major factor in some families not being evaluated by EI. Donna went on to share that in the case of Jayden and his potential to benefit from EI services, she felt like our clinic providers, "sold it well." The idea that family buy-in is critical to follow through was also a major theme across three of the other interviews. However, Donna's quote, in particular, highlights the role of the clinicians in DEC clinic, in what I now imagine as a sort of liaison or ambassador to the EI program and directly responsible for "selling" both the need for EI services and their potential benefit to the child. Amber echoed Donna's sentiment of the DEC clinicians needing to "sell" EI in her suggestions for improvement, recommending that as clinicians we should "definitely press the issue if you know somebody if they think that they actually need it.” As noted previously, Amber's case offers an interesting contrast to Donna's, since Amber originally agreed with the referral, but her concerns resolved shortly after the referral was placed. When asked why she thought some families may not follow through with the EI referral she replied,

It might be a time issue or a distance issue or even maybe financial. In our case, it's just that he all of a sudden started catching on to everything. So, I didn't really think it was necessary. He's doing great so I'm good.

These two cases where children were referred but not evaluated by EI highlight both the importance of the family's opinion regarding their child's need for services. In Donna's case, she and her daughter reportedly felt Caleb needed services and wanted him to be 
enrolled in EI, but other social concerns took precedence (i.e., sorting out a living situation). In Amber's case, she initially agreed with the referral, but didn't end up feeling it was necessary due to a burst of developmental progress.

Similarly, when asked if there is anything that the DEC clinicians could do differently to help connect families to EI, Kelsey replied, "Not really. It's really up to the families. If they don't think this was what the child needs, then they're not going to do anything. They're not going to want to do it." Monica's response to the same question revealed some assumptions regarding what the DEC clinicians are routinely doing to facilitate the EI referral. She replied,

Not that I can really think of. I mean that you guys do like send a referral. I mean you could always like do-I mean I'm sure you guys make phone calls and stuff. I mean, the only thing I can think of would be like send an extra email or send an additional phone call or something just like as a reminder since, like, I know with me, I'm super forgetful. So I have like three kids so I like write down a bunch of stuff and our schedules get busy and then I forget, but that would be the only thing I would think of, but, other than that, nothing.

Monica's response implied that the follow up phone calls I had placed as part of this research study for the past several years (which I mentioned in the interview) are part of the official clinical referral process, which they are not. However, she was the only participant that mentioned placing a follow up phone to check in with the referred family could be helpful. 
Limitations. There were a relatively small number of participants from phase one of the study that could be contacted for this second phase, due primarily to the limited number of referrals placed each year and the need to contact families within a timeframe that it would be reasonable to expect the parent/caregiver would remember both the clinic visit and the initial contact from the EI provider. The families interviewed ended up living all across the state of Oregon. Ultimately, I chose to conduct interviews primarily over the telephone given the follow up timelines for most children in DEC (i.e., one visit per year) and the time/distance to travel to the DEC site at OHSU. However, from my experiences conducting four interviews over the phone and one in-person (in the context of a clinical visit), the in-person interview was not only the most comfortable and natural to conduct, but also seemed to yield the richest and most detailed responses.

As mentioned previously, during the phone interviews, several parent caregivers were caring for young children during the call, with interruptions to answering questions from their child (and/or to redirect a child). Though I cannot speak directly to each participant's perception, this certainly contributed to more perceived time pressure on my part. I was acutely aware of how grateful I was that each participant set aside time to talk to me and I wanted to honor that by keeping the calls short. Another limitation is that several participants communicated difficulty remembering details of the circumstances and outcome of the referral. Ideally, future studies would gather family perspectives at a point in time closer to the actual referral date. Additionally, from this small pool of potential contacts, I was unable to call two of them due to the need for an interpreter, given that using a phone interpreter adds another layer of complexity to the logistics of 
the call and would require additional funding. Though one family was bilingual (English/Spanish), the fact that all parents/caregivers were fluent in English meant that there was no representation from families who would have experienced the added complexity of needing to navigate the referral process through the lens of a non-English speaker. A more culturally and linguistically diverse group of participants would have undoubtedly brought valuable insights to the EI referral process.

The process of contacting these families revealed additional limitations. Chiefly, the phone interview participants consist solely of caregivers who were available to take a phone call in the middle of a weekday. Results of the quantitative phase of the study indicate that the majority of families who do not successfully connect with EI do not return the EI phone call, which is very likely also placed during a workday. Overall, it was much more difficult to contact families who had not been evaluated as a result of the EI referral, indicating there is more work to be done in seeking to understand the experiences of these families and the many factors that may influence their lives. As mentioned previously, my role as a clinician in DEC clinic (and my previous experience meeting four of the families in person) may have had a facilitating effect on their interest in sharing their experiences with me, but it also may have affected how candidly the participants responded. As discussed previously within the context of the interview, I had outsider status, but also carried some level of authority within the power dynamic due to my status within the healthcare system. Though I verbally assured the interviewees that my interests lay in capturing their experience, some participants may have felt unintended pressure to provide a particular response or some level of guilt/responsibility for the child 
not successfully connecting with EI. One parent in particular (Amber) who had not connected to EI occasionally provided (what I interpreted to be) responses that at times came across as a bit defensive. This perception lessened as the interview progressed, as I provided reassurance regarding my motives.

Additionally, my novice interviewing skills were a limiting factor to the amount and depth of the information gathered. Immersion in these interview data via both repeated listening to the audio files as well as re-reading the transcripts revealed many missed opportunities to ask follow-up/clarification questions. There were also several instances in which pausing before moving on to the next question may have resulted in more elaboration on the previous response. Though my interviewing skills improved throughout the course of the study, my inexperience is a limitation that bears mentioning.

The fact that all participants politely declined to participate in member checking procedures is another significant limitation. Though I did my best to faithfully represent my understanding of each participant's intent following immersion of the data and analysis of the transcripts, without participant review of the transcripts and results questions of the validity of results linger. I attempted to check in with participants regarding my understanding of their responses during the interviews, but this practice was not consistently implemented (refer to reference of my novice interviewing skills above).

Finally, the participants of this phase of the study represent only a very small subset of the participants used in the study for this one high risk infant follow up clinic. This phase of the study was intended to highlight and amplify the voices of families 
experiencing one particular referral process. While these cases provide rich context from which to interpret the results from the first phase of the study, they are by no means considered to be representative of all families experiencing this process on a small scale, or more broadly, the experiences of all families who experience their child being referred to EI from a medical practice. However, the experiences and insights shared by these families are intended to open a larger conversation regarding what happens immediately following the identification of a need for EI and initiation of a referral. 


\section{Chapter 5: Discussion}

\section{Synthesis of Findings}

This analysis of EI referral outcomes builds on the previous research investigating EI enrollment rates in high risk populations (Atkins et al., 2017; Blasco et al, 2017; Litt \& Perrin, 2014; Tang et al., 2012) by looking one step backward in the process. While these previous investigations center on who is already enrolled in EI among high risk infants/toddlers, this research study focused on what happens immediately following EI referral placement, with specific interest in learning more about those high risk children who are referred but never evaluated by the program. There has been very little research on this step in the Child Find process in general (Kavanagh et al., 2012), and even less among children who are at increased risk of experiencing delays. Kavanagh et al. (2012) characterizes the leaky pipeline from identification of a need for services to EI enrollment well by stating, "This process is often impeded by procedural barrier and poor coordination across child-serving systems, resulting in large numbers of children dropping off along the pathway from screening to service” (p. 8).

Results from the quantitative phase of this study serve to illustrate the extent of the challenge in connecting families of children at increased risk for experiencing developmental delays with EI services by investigating the critical step between placing an EI referral and obtaining an EI eligibility evaluation. Strikingly, only slightly more than half $(62 \%)$ of the infants/toddlers who were referred for EI services were evaluated by the program. Though this represents twice the percentage of successful referrals when compared to one study looking at EI referrals resulting in evaluation among the general 
population (Jimenez et al., 2014), this is still lower than expected given that this study centers on children whose medical histories place them at significant risk of experiencing developmental delays. The percentage of children evaluated by the EI program is also lower than previous research using linked data to investigate EI referral outcomes in the first year of life in Massachusetts (Clements et al., 2006).

Previous research investigating factors associated with EI enrollment for LBW children found significant relationships between several medical risk factors (i.e., lower birth weight, younger gestational age, longer NICU stay), as well as developmental status and likelihood of being enrolled in EI (Atkins et al., 2017; Blasco et al, 2017; Litt \& Perrin, 2014; Tang et al., 2012). However, the only statistically significant factor related to likelihood that a child was evaluated as a result of an EI referral in this sample was birth weight. Though birth weight was the only statistically significant factor identified in this study, the motor composite score may emerge as a significant factor in a larger sample, with more statistical power. The fact that the motor composite and birth weight were not significantly correlated suggests that each of these factors may be providing a unique contribution to the likelihood of a child being evaluated as part of the referral. It would be interesting to extend the study for a few more years and/or work with other high risk infant follow up clinics to explore these potential relationships more with a larger sample.

Previous research has also suggested that LBW children with public insurance are more likely to be enrolled in EI (Atkins et al., 2017; Tang et al., 2012; Wang et al., 2009), which was also not the case in this sample. In general, the literature suggests there are 
more readily available patterns regarding which children ultimately are evaluated and eligible for EI than those children who are either never referred, or referred but do not connect with the program. Results from the follow up phone call indicate the majority of families (64\%) who are never evaluated as a result of referral simply do not return a phone call, though scheduling issues (i.e., canceling an appointment or failing to show up for an appointment) make up another $10 \%$ of reasons families are not connected. Most of the "other" reasons for not being evaluated through EI centered on logistics (i.e., the family had moved), or the child was deemed too close to the age at which he/she would be transitioning into ECSE services. Only $18 \%$ of families actively declined the EI evaluation. These findings are roughly consistent with the limited information available on parental report on reasons a LBW child is not in EI, though only $3 \%$ of families in previous research on this topic reported not remembering successfully being contacted by EI (Blasco et al., 2017), while this study indicates families not returning the EI phone call to be a significant factor in missed opportunities following referral. Overall, results from the quantitative component suggest there is no clear cut way to predict which children referred to EI as the result of an evaluation through a high risk infant follow up program are at the highest risk of not following through on the referral. However, in this study the simple act of following up on the referral had a powerful effect, as there were three cases in which follow up call revealed that the original referral had either been faxed incorrectly or EI had never received the fax. These errors were easily rectified as a result of the call, but may not have otherwise been discovered. 
While the quantitative results served to better characterize the challenge of connecting children to EI from a high risk infant follow up program, the qualitative interviews were instrumental in illuminating the nuanced experiences of families of high risk children who had been referred to EI. While this small sample highlights the postreferral experiences of just a few families, the process of contacting and interviewing these families provided valuable insights into why some families of high risk children do not connect with EI services following referral. Ultimately, the themes from interviewing families indicate that the most important factor determining follow through on an EI referral is the family's perception regarding their child's need for EI services and their perception of the potential benefit of participating in the program. Previous research utilizing qualitative interviews with nine pediatricians also found that parent concern regarding their child's developmental progression could significantly promote or discourage a family from following up with EI (Jimenez et al., 2014). However, the pediatricians interviewed by Jimenez et al. (2014) noted their office's particular procedures for developmental screening and placing referrals weighed heavily into their perception of the likelihood of EI referral resulting in evaluation. This was not evident in this study through interviews with the families, though this particular high risk infant follow up program was already implementing a referral system that included faxing EI referral forms directly to EI programs (rather than providing the family with a phone number), which was a primary recommendation from previous research (Jimenez et al., 2014; Little et al., 2015). 
Interpreting the importance of family perception of the need for the referral and the potential for benefit in the EI program in the context of the quantitative results indicates many implications for improving the EI referral process. Importantly, that a portion of the referrals placed appear to have been unlikely to result in EI enrollment, given the documentation from the visit did not support eligibility. Additionally, some of the children who were never evaluated may have had similar experiences to Amber's, in which concerns resolved shortly after the referral was placed. One important avenue for improvement is to increase the acumen of the referrals placed in clinic (i.e., making sure referrals are only placed when scores on developmental testing and/or documented medical history suggest that a child is likely to meet eligibility criteria). This should include provider education regarding local EI eligibility requirements to ensure that providers are only placing referrals that are likely to result in eligibility through the program, increasing the credibility of the referrals placed. This should also include a structured protocol for placing the referral (ideally with written instruction regarding EI eligibility requirements and where to document them on the form) and a process for dedicating support staff to follow up on the referral.

The qualitative interviews also served to highlight the complex needs of families with children born LBW/premature. As illustrated in Donna's interview and echoed in the interviews with the other participants, there are many factors that can influence a family's ability to connect with EI at a particular point in time. For example, despite Donna (and reportedly Sharon's) interest in having Jayden connect with the local EI program, concerns regarding housing stability and medical care coordination took 
precedence. This was consistent with themes reported from focus groups that included parents of children referred to EI that included wariness of home visits (also reported by Donna as a potential factor) and social concerns (Little et al., 2015). However, Little et al. (2015) also reported some parents shared a perception that EI services are not helpful as a barrier to participation, which was not consistent with findings from the qualitative phase of this study. All of the parents/caregivers participating in EI in this study (or who had prior experience with EI for a different child) reported a positive experience with the program and characterized EI services as helpful for their child.

\section{Implications for Practice}

There are many clinical quality improvement implications of this research, which are explored here using relevant aspects of the Chronic Care Model (CCM) as a conceptual framework to structure the recommendations for practice (Bodenheimer, Wagner, \& Grumbach, 2002).

Self-management support. As described in chapter two, one of the chief tenets of the CCM is empowering patients and their families take responsibility for their/their child's health needs (Bodenheimer et al., 2002). A critical aspect of self-management support for families of children born LBW and/or deemed at high risk of experiencing developmental delays is evaluating the family's access to developmental support and referring them to EI as necessary. A central theme of the interviews with families was the idea that clinicians may be experts on development, but parents/caregivers are the expert when it comes to their particular child. In order to empower families to be effective selfmanagers of their child's care, it is essential that clinic visits include ample time for the 
clinical team to provide feedback on the results from developmental testing and recommendations following the visit, including the facilitation of an EI referral. As illustrated in the qualitative interviews, the single most powerful theme was the need for parents to understand the purpose of the EI referral and the rational of the need for services. While the interviewed families indicated understanding of the referral and did not explicitly state the need for additional feedback time, families consistently referred to the need for providers to "sell" the idea of EI to families.

One of the parents whose child was referred to EI but never evaluated (Amber) shared that she did not understand the purpose of the EI referral in relation to the DEC evaluation process. If referrals are placed to community supports, such as EI, the clinical team should provide a thorough explanation of both the referring concerns and the purpose of the EI program. Interviews with one of the two families interviewed who did not successfully connect to EI communicated limited understanding of the purpose of EI services, or the difference between EI programs and the DEC program. Families whose children had been served by EI communicated sincere gratitude at being connected to the program, with Valencia stating, "We are so thankful that you guys helped us get with Early Intervention. David has made so much progress since he started there."

Community resources. As discussed in chapter two, one of the most critical element of the $\mathrm{CCM}$ as it relates to providing innovation in the way $\mathrm{LBW} /$ premature care is received and developmental supports given, is the need to provide community linkages (Bodenheimer et al., 2002). For LBW children and their families, an important community linkage is often the connection to EI. Currently, providers in Oregon have 
access to a state-specific universal referral form, though it is unclear how many practices actually use the form. One a large scale, one clear area for improvement would be strengthening the communication between the local EI programs and medical providers by creating a more streamlined referral process. The DEC program uses this referral form, though the mechanism for submitting the form is dated (see Clinical Information Systems below). However, a good place to start on a smaller scale would be to have a standardized, written protocol for placing EI referrals that included designating the responsibility regarding EI referral follow up to a support staff member and having the protocol include follow up with both the EI program and the family.

As discussed previously, one of the most consistent themes in the qualitative interviews was the need for parents to understand the rationale for the referral and agree that their child could benefit from services. A key part of selling the concept of EI services to families is making sure that parents/caregivers understand why their child is being followed through the DEC program, why they would like to refer the child to EI, and what services EI would provide.

Clinical information systems. Though electronic medical record (EMR) systems are prevalent in larger health systems (including OHSU), they are often not utilized at their full capacity (Hsiao, \& Hing, 2014). While the DEC clinic does use EMR for many aspects of patient care, there is currently no system in place to clearly document referrals placed to EI, nor does it utilize automatic reminders. There is also no consistently used system for ensuring that EI referral forms are scanned into the medical record. Ideally, a standardized referral protocol will be created that will include documentation of the 
referral, and a flagging system for providers to know to follow up on the status of the referral at the next visit to clinic. This protocol should also include a reliable system for having referral forms scanned into the child's medical record. The reliance on paper tracking and referral systems in the DEC program is a significant disadvantage.

One recent study by Conroy et al. (2018) details how Boston Children's Hospital increased their EI referral success in their clinical programs from a baseline of 50\% to $70 \%$ by instituting a complete overhaul of their EI referral system. One key change they made was implementing a centralized electronic referral system that allowed providers to route EI referral requests through the EMR to patient navigators, who processed the referrals and track referral outcomes using a newly created EI registry. A similar system could be implemented across OHSU, eliminating many of the logistical challenges with making sure referrals are timely and accurate. However, a smaller scale solution for follow up clinics (who are processing a much more manageable amount of referrals than a primary care office), could include training an existing support staff member or social worker to process and track the referrals in central location on the secured drive.

Delivery system redesign and decision support. In order to allow time for more chronic healthcare needs (including screening for developmental delays and connecting families to appropriate resources), the medical practice must be structured in a way that allows for dedicated time to address these concerns, rather than defaulting to prioritization of more acute health needs (Bodenheimer et al., 2002). Anecdotally, several of colleagues in the DEC have reported that recent increases in productivity requirements have resulted in shortened visits and less time for giving feedback to families. By 
creating a standardized referral system that includes bringing in a support staff person to facilitate the referral, clinicians could focus less on the logistics of the referral and more time on parent education regarding the reason for the referral and the purpose of EI. This could also help reduce the time pressures of clinicians with stringent productivity requirements by using support staff services to explain the logistical aspects of the referral and help the family fill out the referral form, allowing the clinician to spend more time providing the family with specific developmental feedback from the visit, providing a solid rationale for the EI referral, and explaining the EI program and the potential benefits of participation.

\section{Future Directions}

Though this research has revealed many interesting insights regarding EI referral outcomes for high risk children (particularly those born LBW), more research is needed. Specifically, research is needed to better characterize the children and families who are not successfully connected to EI across other clinical settings. Given the many regional factors involved in this research, it would be ideal to have a multiple site investigation with a larger group of participants. Similarly, more research is needed to document the outcome of efforts to implement hospital and community-wide systems for increasing efficiency and success of EI referrals, through a public health and quality improvement lens. Ideally, hospital systems would be able to build on the success of Conroy et al. (2018) in streamlining the referral process and utilizing support staff personnel to facilitate, track, and follow up on EI referrals. In terms of serving high risk infant/toddlers in particular, a critical next step in understanding EI referral outcomes 
would be to look backward at the earliest opportunities for EI referral. At present, there are no studies investigating EI referral outcomes from the NICU, which represents the first possible referral opportunity for the majority of high risk infants, many of whom can be identified as being at increased risk of experiencing developmental delays immediately after birth.

Perhaps most importantly, more qualitative research investigating the specific experience of families of children with medical conditions that place them at increased risk of experiencing developmental delays is needed in order to better understand the many different factors influencing a family's access to services. Specifically, more research is needed to highlight the voices of those families who are not successfully connected with EI. More research is also needed investigating the EI referral experiences of more culturally and linguistically diverse families, as previous research has indicated that parents/caregivers who speak a language other than English have more difficulty connecting with EI (Williams et al., 2013). Well-conducted research exploring the experiences of families will ensure that the time, thought, and effort that goes into implementing widespread systems yields maximum benefit and reaches the most vulnerable children and families.

\section{Conclusions}

Children with complex early medical histories (including low birth weight and prematurity) who are readily identified shortly after birth as being at risk for experiencing developmental delays have significant difficulty connecting appropriately with EI services, even when followed by high risk infant follow up clinics. As discussed in 
Chapter Two and illuminated through analysis of the research findings presented here, the CCM provides an excellent framework for analyzing the potential breakdown points in the EI referral process and organizing recommendations for change. While CCM focuses on the practical areas to assess when evaluating the health system, EST provides a means of conceptualizing the importance of the connections between the health system, the EI program, and the family. When conceptualized through this model, the connection between parents/caregivers and EI is not only critical, but also vulnerable given that a significant theme from this study was the family's role in mediating the family's relationship with a high risk infant follow up program (a significant EI referral source for high risk infants and toddlers). 


\section{References}

American Academy of Pediatrics Committee on Children with Disabilities. (2001).

Developmental surveillance and screening of infants and young children.

Pediatrics, 108(1), 192-196. doi: 10.1542/peds.108.1.192

American Academy of Pediatrics (2006). Identifying infants and young children with developmental disorders in the medical home: An algorithm for developmental surveillance and screening. Pediatrics, 118(1), 405-420. doi: 10.1542/peds.20061231

Atkins, K. A., Duvall, S. W., Dolata, J. K., Blasco, P. M., \& Saxton, S. N. (2017). Part C early intervention enrollment in low birth weight infants at risk for developmental delays. Maternal and Child Health Journal, 21(2), 290-296. doi: 10.1007/s10995$016-2113-y$

Bailey, D. B., Hebbeler, K., Scarborough, A., Spiker, A., \& Mallik, S. (2004). First experiences with early intervention: A national perspective. Pediatrics, 113, 887-896. doi: 10.1542/peds. 113.4 .887

Bailey, D. B, Hebbeler, K., Scarborough, A., Spiker, A., Mallik, S., \& Nelson, L. (2005). Thirty-six-month outcomes for families of children who have disabilities and participated in early intervention. Pediatrics, 116, 1346-1352. doi: 10.1542/peds.2004-1239

Barfield, W. D., Clements, K. M., Lee, K. G., Kotelchuck, M., Wilber, N., \& Wise, P. H. (2008). Using linked data to assess patterns of Early Intervention (EI) referral 
among very low birth weight infants. Maternal Child Health Journal, 12(1), 2433. doi:10.1007/s10995-007-0227-y

Barre, N., Morgan, A., Doyle, L. W., \& Anderson, P. J. (2011). Language abilities in children who were very preterm and/or very low birth weight: A meta-analysis. The Journal of Pediatrics, 158(5), 766-774. doi: 10.1016/j.peds.2010.10.032 Bayley, N. (2005). Bayley scales of infant and toddler development-third edition. San Antonio: The Psychological Corporation.

Blasco, P. M., \& Saxton, S. N., (2009). Examining developmental/behavioral ability in infants and toddlers born premature and low-birth-weight (LBW). Portland, OR: IRB approved database. Oregon Health \& Science University.

Blasco, P. M., Guy, S., Saxton, S., \& Duvall, S. (2017). Are we missing a vulnerable population in early intervention? Infants and Young Children, 30(3), 190-203. doi: 10.1097/IYC.0000000000000097

Bodenheimer, T. \& Pham, H. H. (2010). Primary care: Current programs and proposed solutions. Health Affairs, 29, 799-805. doi: 10.1377/hlthaff.2010.0026

Bodenheimer, T., Wagner, E. H., \& Grumbach, K. (2002). Improving primary care for patients with chronic illness. JAMA, 288, 1775-1779.

doi:10.1001/jama.288.14.1775

Bronfenbrenner, U. (1979). The ecology of human development. Cambridge, MA: Harvard University Press. 
Bronfenbrenner, U. (1989). Ecological systems theory. In R. Vasta (Ed.), Annals of child development: Theories of child development: Revised formulations and current issues (pp. 187-251), Greenwich, CT: JAI press.

Bronfenbrenner, U., \& Morris, P. A. (1998). The ecology of developmental processes. In R. M. Lerner (Ed.), Handbook of child psychology: Vol. 1. Theoretical models of human development ( th $^{\text {ed., }}$ pp. 535-584). New York, NY: Wiley.

Coleman, K., Austin, B. T., Brach, C., \& Wagner, E. H. (2009). Evidence on the chronic care model in the new millennium. Health Affairs, 28(1), 75-85. doi:10.1377/hlthaff.28.1.75

Conroy, K., Rea, C., Kovacikova, G. I., Sprecher, E., Reisinger, E., Durant, H., ...Toomey, S. L. (2018). Ensuring timely connection to early intervention for young children with developmental delays. Pediatrics, 142(1), 1-8. doi: 10.1542/peds.2017-4017

Clements, K. M., Barfield, W. D., Kotelchuck, M., Lee, K. G., \& Wilbur, N. (2006). Birth characteristics associated with early intervention referral, evaluation for eligibility, and program eligibility in the first year of life. Maternal Child Health Journal, 10, 433-441. doi: 10.1007/s10995-006-0080-4

Creswell, J. W. (2014). Research design: Qualitative, quantitative, and mixed methods approaches. Los Angeles: Sage.

Creswell, J. W. (2015). A concise introduction to mixed methods research. Thousand Oaks, CA: Sage. 
Division for Early Childhood of the Council for Exceptional Children (2017). Position statement on low birth weight, prematurity and early intervention. Retrieved from http://www.dec-sped.org/single-post/2018/10/15/New-Position-Statement-DECPosition-Statement-on-Low-Birth-Weight-Prematurity-EarlyIntervention?fb_comment_id=2031211486920435_2033724943335756

Duvall, S. W., Erickson, S.J., MacLean, P., \& Lowe, J. R. (2015). Perinatal medical variables predict executive function within a sample of preschoolers born very low birth weight. Journal of Child Neurology, 30, 735-740. doi: $10.1177 / 0883073814542945$

Field, A. (2018). Discovering statistics using IBM SPSS statistics, fifth editon. London: Sage Publications.

Goodman, R. A., Posner, S. F., Huang, E. S., Parekh, A. K., \& Koh, H. K. (2013). Defining and measuring chronic conditions: Imperatives for research, policy, program, and practice. Preventing Chronic Disease, 10, 1-16. doi:10.5888/pcd10.120239

Guarini, A., Sansavini, A., Fabbri, C., Alessandroni, R., Faldella, G., \& Karmiloff-Smith, A. (2009). Reconsidering the impact of preterm birth on language outcome. Early Human Development, 85, 639-645. doi:10.1016/j.earlhumdev.2009.08.061

Hagan, J., Shaw, J. S., \& Duncan, P. M. (Eds.). (2017). Bright Futures: Guidelines for health supervision of infants, children, and adolescents. $4^{\text {th }}$ Ed. Elk Grove Village, IL: American Academy of Pediatrics. 
Hebbeler, K., Spiker, D., Scarborough, A., Mallik S., Simeonsson R., Singer M., \& Nelson L. (2007). National early intervention longitudinal study (NEILS) final report. Menlo Park, CA: SRI Publication.

Hsiao, C., \& Hing, E. (2014). Use and characteristics of electronic health record systems among office-based physician practices (NCHS data brief No. 143). Hyattsville, MD: National Center for Health Statistics.

Hutchinson, E. A., De Luca, C. R., Doyle, L. W., Roberts, G. \& Anderson, P. J. (2013). School- age outcomes of extremely preterm or extremely low birth weight children. Pediatrics, 131, 1053-1061. doi:10.1542/peds.2012/2311

Individuals with Disabilities Education Act, 20 U.S.C. $§ 1400$ (2004).

Ivankova, N. V., Creswell, J. W., \& Stick, S. L. (2006). Using mixed-methods sequential explanatory design: From theory to practice. Field Methods, 18(1), 3-20. doi: $10.1177 / 1525822 X 05282260$

Jimenez, M. E., Fiks, A. G., Ramirez Shah, L., Gerdes, M., Ni, A. Y., \& Guevara, J. P. (2014). Factors associated with early intervention referral and evaluation: A mixed methods analysis. Academic Pediatrics, 14(3), 315-323. doi: 10.1016/j.acap.2014.01.007.

Jin, J. (2015). Babies with low birth weight. Journal of the American Medical Association, 313 (4), 432. doi: 10.1001/jama.2014.3698

Johnson, E. (2008). Ecological systems and complexity theory: Toward an alternative model of accountability in education. Complicity: An International Journal of Complexity and Education, 5(1), 1-10. 
Johnson, S. (2007). Cognitive and behavioural outcomes following very preterm birth. Seminars in Fetal and Neonatal Medicine, 12, 363-373. doi:10.1016/j.siny.2007.05.004

Kavanagh, J., Gerdes, M., Sell, K., Jimenez, M., \& Guevara, J. (2012). SERIES: An integrated approach to supporting child development (Summer issue). Retrieved from the Children's Hospital of Philadelphia PolicyLab website: https://policylab.chop.edu/sites/default/files/pdf/publications/PolicyLab_EtoA_SE RIES_Developmental_Screening_Summer_2012.pdf.

Lee, E. S., Yeatman, J. D., Luna, B., \& Feldman, H. M. (2010). Specific language and reading skills in school-aged children and adolescents are associated with prematurity after controlling for IQ. Neuropsychologia, 49, 906-913. doi:10.1016/j.neuropsychologia.2010.12.038

Litt, J. S., Glymour, M. M., Hauser-Cram, P., Hehir, T., \& McCormick, M. C. (2017). Early intervention services improve school-age functional outcomes among NICU graduates. Academic Pediatrics. Advance online publication. doi: 10.1016/j.acap.2017.07.011.

Litt, J. S. \& Perrin, J. M. (2014). Influence of clinical and sociodemographic characteristics on early intervention enrollment after NICU discharge. Journal of Early Intervention, 36(1), 37-48. doi:10.1177/1053815114555575

Little, A. A., Kamholz, K., Corwin, B. K., Barrero-Castillero, A., \& Wang, C. J. (2015). Understanding barriers to early intervention services for preterm infants: Lessons from two states. Academic Pediatrics, 15, 430-438. doi:10.1016/j.acap.2014.12.06 
Lowe, J., Erickson, S. J., MacLean, P., Duvall, S. W., Ohls, M. D., \& Duncan, A. F. (2014). Associations between maternal scaffolding and executive functioning in 3 and 4 year olds born very low birth weight and normal birth weight. Early Human Development, 90, 587-593. doi: 10.1016/j.earlhumdev.2014.07.009

Luttikhuizen dos Santos, E. S., de Kieviet, J. F., Konigs, M. van Elburg, R. M., \& Oosterlaan, J. (2013). Predictive value of the Bayley scales of infant development on development of very preterm/very low birth weight children: A meta-analysis. Early Human Development, 89, 448-496. doi: http://dx.doi.org/10.1016/j.earlhumdev.2013.03.008

Macy, M. Bagnato, S. J., Macy, R. S., \& Salaway, J. (2015). Conventional tests and testing for early intervention Eligibility: Is there an evidence base? Infants and Young Children, 28(2), 182-204. doi: 10.1097/IYC.0000000000000032

Martin J. A., Hamilton B. E., Osterman, M. J. K., Driscoll, A. K., \& Drake, P. (2018). Births: Final data for 2016. National vital statistics reports; 67(1), Hyattsville, MD: National Center for Health Statistics.

Maxwell, J. A. (2012). Qualitative research design: An interactive approach (Vol. 41). Thousand Oaks, CA: Sage.

McManus, B. M., \& Rosenberg, S. A. (2012). Does the persistence of developmental delay predict receipt of early intervention services? Academic Pediatrics, 12, 546550. doi: 10.1016/j.acap.2012.07.003

Miles, M. B., Huberman, M., \& Saldaña J. (2014). Qualitative data analysis: A methods sourcebook (3rd ed.). Thousand Oaks, CA: Sage. 
Merriam, S. B., \& Tisdell, E. J. (2016). Qualitative research: A guide to design implementation (4th ed.). San Francisco, CA: Jossey-Bass.

Oregon administrative rules, chapter 166, division 500, rule 0020 is cited as OAR 166500-0020. http://sos.oregon.gov/archives/pages/about_rules.aspx. Accessed 2 February 2018.

Oregon Revised Statute, Chapter 334, Number 334.005, cited as ORS 334.005

Rosenberg, S. A., Robinson, C. C., Shaw, E. F., \& Ellison, M. C. (2013). Part c early intervention for infants and toddlers: Percentage eligible versus served. Pediatrics, 131 (1), 38-46. doi: 10.1542/peds.2012-1662

Rosenberg, S. A., Zhang, D., \& Robinson, C. C. (2008). Prevalence of developmental delays and participation in early intervention services for young children. Pediatrics, 121, 1503-1509. doi:10.1542/peds.2207-1680

Shaffer, D. R. (2005). Social and personality development ( $5^{\text {th }}$ ed.). Belmont, CA: Thomson Wadsworth.

Shapiro, B. J., \& Derrington, T. M. (2004). Equity and disparity in access to services: An outcome-based evaluation of early intervention child find in Hawai'i. Topics in Early Childhood Special Education,24, 199-212. doi: $10.1177 / 02711214040240040201$

Silverstein, M., Sand, N., Glascoe, F. P., Gupta, V. B., Tonniqes, T. P., \& O'Connor, K. G. (2006). Pediatrician practices regarding referral to early intervention services: is an established diagnosis important? Ambulatory Pediatrics, 6(2), 105-109. doi:10.1016/j.ambp.2005.09.003 
Tang, B. G., Feldman, H. M., Huffman, L. C., Kagawa, K. J., \& Gould, J. B. (2012). Missed opportunities in the referral of high risk infants to early intervention. Pediatrics, 129, 1027-1034. doi:10.1542/peds.2011-2720

Travis, K. E., Ben-Shachar, M., Myall, N. J., \& Feldman, H. M. (2016). Variations in the neurobiology of reading in children and adolescents born full term and preterm. NeuroImage: Clinical, 11, 55-565. doi: 10.1016/j.nicl.2016.04.003

Twardzik, E., Cotto-Negron, C., \& MacDonald, M. (2017). Factors related to early intervention part C enrollment: A systematic review. Disability and Health Journal, 10, 467-474. doi: 10.1016/j.dhjo.2017.01.009

Wang, C. J., Elliott, M. N., Rogowski, J., Lim, N. Ratner, J. A., \& Schuster, M. A. (2009). Factors influencing the enrollment of eligible extremely-low-birthweight children in the Part C Early Intervention program. Academic Pediatrics, 9, 283-287. doi: 10.1016/j.acap.2009.04.001

U.S. News. (2018). Best hospitals for neonatology. Retrieved from: https://health.usnews.com

Watling Neal, J. \& Neal, Z. P. (2013). Nested or networked? Future directions for ecological systems theory. Social Development, 22, 722-737. doi:10.1111/sode. 12018

Weiss, R. S. (1994). Learning from strangers. New York: Free Press.

Williams, M. E., Perrigo, J. L., Banda, T. Y., Matic, T., \& Goldfarb, F. (2013). Barriers to accessing services for young children. Journal of Early Intervention, 35(1), 6174. doi: $10.1177 / 105381511350711$ 


\section{Appendix A: Interview Protocol \\ Telephone Recruitment and Screening Script Template}

Hello, my name is . I'm calling from Oregon Health \& Science

University about a research study. Am I speaking to (name of recruit)?

If "no," wait for recruit to pick up, arrange to leave a message, or ask for a time to call back.

If "yes":

I am one of the providers working in the Developmental Evaluation Clinic at Oregon Health and Science University where _____ (child's name) was seen on (date). Is this a good time to talk? I expect this phone call will take about _ $\underline{10}$ minutes.

Arrange to call at another time, if appropriate.

I'm calling from the Developmental Evaluation Clinic at OHSU about a research study where we are following up on the status of referrals we place from clinic to Early Intervention. The purpose of this study is to learn more about what is happening to the referrals we place to Early Intervention and see if we can learn more about how to connect families more successfully to the program. My records show that we referred your child to Early Intervention as part of a DEC clinic visit. Can I discuss the study with you in more detail, and you can decide if you want to participate?

Before we go on to the questions, let me tell you a little bit about your rights as a research subject. 
The main risk of answering my questions today is loss of confidentiality. However, we will do our best to keep your information confidential by removing your name and your child's name from any of the information we store. All of our data will be stored on a secured drive on a password-protected computer. There will be no record in your child's electronic medical chart of this phone call, regardless of your decision to participate or not.

You do not have to answer any of the questions, and you can choose to stop at any time without penalty. If you have questions about the study, you can call me at 503-4180689. If you have questions about your rights as a research subject or research-related injuries, you can call the OHSU Research Integrity Office at 503-494-7887.

May I go ahead explain the study in further detail to you?

\section{If no, thank the individual and end the call.}

\section{If yes:}

I have questions for you that I anticipate will take about 10-20 minutes to answer. Would you like me to ask them now, or would you rather we schedule a different time?

\section{Script for Interview Questions:}

Thank you: Thank you for agreeing to talk to me today. I know that you are very busy and I appreciate you taking the time to share your experiences with me. As I mentioned earlier, I am working on a project investigating the experiences of families who have been referred to Early Intervention from the Developmental Evaluation Clinic at OHSU. I am hoping to gain more information from the families we have referred about what 
happened after we placed the referral, with the goal of looking into ways that we could help connect more families to EI.

Confidentiality: I will be using a recording device for this interview so that I can focus on listening and then review what we discuss later. No one outside of my research team will be listening to the recording and again, I will redact the transcript of this phone call so that it does not include your name or your child's name. I will be also be careful to exclude any information that might identify you or your child from the transcript of this call. Is it okay with you that I record this session? Do you have any questions for me before I start the recording?

Recording: I am starting the recording now.

\section{Provisional Interview Questions:}

\section{Referral Process}

- Introductory Probe: [name] was [age] old when he was seen in clinic. How old is he/she now? What's something new that you have noticed your child learning or doing lately?

- I would like to learn about your experience being referred to EI from the Developmental Evaluation Clinic at OHSU. My records show that we saw [child's name] on [date] and referred him/her to EI. Talk me through what happened when the provider was telling you the results from the evaluation and talking to you about the EI referral. 
- Do you remember being contacted by the EI program? How did that phone call go?

- How did you decide whether or not to call them back?

\section{Thoughts/Feelings regarding the referral and interest/response to EI}

- What is your understanding of why [child's name] was referred to EI?

- $\quad$ How did you feel about [name] being referred to EI?

- Did you have any concerns about participating in the EI program? Were they addressed during the DEC clinic visit?

\section{Understanding of Roles}

- I would like to learn more about your understanding of the relationship between the DEC Clinic and the EI program and what roles they each might have in [name's] life.

- What is your understanding of why [name] was seen in the DEC clinic?

- What role do you think the DEC clinic will play for your family during [name's] early years?

- When you were contacted by EI program what was your understanding of the purpose of the evaluation?

- What kinds of things do you think EI might help a family with?

\section{Ideas regarding improvement}

- I would like to learn more about your thoughts regarding why some families have their children evaluated by EI and some do not.

- About half of the families we refer to EI end up being evaluated through the program. Based on your experience, what factors do you think might lead a family to having their child evaluated?

- Similarly, about half of the families we refer to EI do not end up having their child evaluated through the EI program. Again, based on your experience, 
what factors do you think might lead to a family not having their child evaluated?

- Do you think there is anything we could do differently to help connect families to EI?

- Is there anything else you want us to know about your experience being referred to EI from the OHSU DEC clinic?

- $\quad$ Do you have any questions for me?

Thank you so much for agreeing to speak with me about your experience being referred to Early Intervention from the Developmental Evaluation Clinic at OHSU. If you have any additional questions, please contact Kristi Atkins, MA, CCC-SLP at 503-418-0689. 


\section{Appendix B: Final Code List}

Final Codes

\begin{tabular}{|c|c|}
\hline Elemental Codes & Abbreviations \\
\hline \multicolumn{2}{|l|}{ Descriptive } \\
\hline Developmental Evaluation Clinic Role & DEC-ROLE \\
\hline Developmental Evaluation Clinic Benefits & DEC-BEN \\
\hline Early Intervention Role & EI-ROLE \\
\hline Early Intervention Benefits & EI-BEN \\
\hline Developmental Progress & DEV-PROG \\
\hline Developmental Strength & STRNGTH \\
\hline Parental Goal & GOAL \\
\hline Developmental Delay & DEV-DLY \\
\hline Family Stressor & FMLY-STRSS \\
\hline Facilitating Factor & FAC:FACT \\
\hline Barrier to Care & BAR: CARE \\
\hline Connection & CONN \\
\hline Improvement IDEA & IMP:IDEA \\
\hline Rationale & RAT \\
\hline Previous EI experience & PREV: EI \\
\hline Parent Responsibility & PAR: RESP \\
\hline Problematic Behavior & PROB: BEH \\
\hline Child-centered & CHILD CNTRD \\
\hline Professionals & PROS \\
\hline Justification & JUSTIFY \\
\hline \multicolumn{2}{|l|}{ In Vivo } \\
\hline "Busy" & "BUSY” \\
\hline "A lot better" & “BETTER” \\
\hline "Picked up quickly" & “PICKEDUP” \\
\hline "Top priority" & “PRIORITY” \\
\hline "Difficult" & “DIFFICULT” \\
\hline "Our business" & “OUR BIZ” \\
\hline “Smart" & "SMART" \\
\hline "Forget" & “FORGET”, \\
\hline "Wasn't worried anymore" & "NO WORRY” \\
\hline \multicolumn{2}{|l|}{ Process } \\
\hline Coordinating care & $\mathrm{CC}$ \\
\hline Scheduling & SCHED \\
\hline Caregiving burden & CARE-BURD \\
\hline Convincing & CONVINCE \\
\hline
\end{tabular}




Affective Codes
Emotion
Concern/Worry
Disagreement
Agreement
Confusion
Denial
Shame
Fatigue
Happy
Gratitude
Burden
Excitement
Uncertainty
Apathy

Values (V: value, A: attitude, B: belief)

B: "doing well"

A: "don't need help"

A: "need help"

A: "anything to help"

$\mathrm{V}$ : "top priority"

\section{Evaluation}

Positive EI Experience

Positive DEC Experience

Negative Developmental Progress

Positive Developmental Progress
CONC

DSGR

AGR

CONF

DENIAL

SHAME

FATG

HAP

GRAT

BURD

EXCIT

UNSR

APTHY

B: WELL

A: NO-HELP

A: HELP

A: ANY HELP

$\mathrm{V}$ : TOP

+ EI: EXP

+ DEC: EXP

- DEV-PROG

+ DEV-PROG 